\title{
A Two-Dimensional Conductivity Model across Central Japan
}

\author{
Hisashi Utada, Yozo Hamano, and Takesi Yukutake \\ Earthquake Research Institute, University of Tokyo, Bunkyo-ku, Tokyo, Japan
}

(Received January 14, 1986)

\begin{abstract}
Horizontal profiles of geomagnetic transfer function were obtained at the periods of 15, 30, 60 and 120 minutes by analysing 3-component geomagnetic variation data at 21 sites in the central part of Japan and 7 sites on the Philippine Sea floor. A two-dimensional conductivity model was constructed, by use of the finite element method, to represent the spatial and period dependence of these transfer functions.

Characteristics of the observed transfer functions on the Pacific coast and continental shelf of the Philippine Sea were well explained by introducing a highly conductive layer beneath the Philippine Sea plate at a depth of about $30 \mathrm{~km}$ in addition to a large conductivity contrast between land and seawater. In order to account for the anomalous phase variation observed at the northern half of the central Japan sites, conductive lower crust was required beneath this region. This lower crustal conductor also explained the reduction of the coast effect on the Japan sea coast, and the existence of free water in the lower crust was considered as its likely cause. Our result did not require the conductive upper mantle beneath the Japan Sea, at least $200 \mathrm{~km}$ away from the coast, to explain the data, which may suggest that the plate motion is the possible cause of highly conductive asthenosphere as well as the partial melting.
\end{abstract}

\section{Introduction}

Since RIKITAKE and YOKOYAMA (1953) pointed out the anomalous behavior of vertical component of geomagnetic variation at short periods in the central Japan area, many studies have been made to make clear the subsurface electrical conductivity structure in this region (e.g., RIKITAKE and HONKURA, 1973; RIKITAKE, 1969, 1975; HONKURA, 1974). Conductivity models proposed in these studies have a common feature; i.e. there exist highly conductive layers in the upper mantle beneath both the Japan Sea and the Philippine Sea, while the conductor is depressed beneath Central Japan. The cause of the highly conductive layer is generally attributed to high temperature or partial melting in the upper mantle (HONKURA, 1974, 1975), which is consistent with the distribution of heat flow values around the Japanese islands (WATANABE, 1968). Besides these highly conductive layers beneath the oceanic plates, previous geomagnetic observations, in both spatial and frequency dependencies, have been explained by the coast effect due to the conductive sea water.

In 1982, Research Group for Crustal Resistivity Structure, Japan, carried out magnetometer array observation at 16 sites in Central Japan (YUKUTAKE, 1984). Magnetotelluric responses at ELF and VLF frequency ranges were also obtained at these sites to reveal the surface conductivity structure. In addition to these land 
measurements, observations of geomagnetic variations have been conducted every year on the sea floor off the southern coast of Central Japan since 1983 by use of newly developed ocean bottom magnetometers (OBM)(SEGAWA et al., 1982). In the present paper, the electrical conductivity structure beneath this area, including surrounding seas, is examined on the basis of not only newly acquired geomagnetic variation data, but also those previously obtained.

A two-dimensional finite element method will be applied to calculate the theoretical responses in order to determine a geoelectrical model which explains spatial and temporal characteristics of the observed geomagnetic variations. In this analysis, most effort has been concentrated on clarifying the following;

1) Conductivity structure beneath the Philippine Sea plate which is subducting below the Japanese islands.

2) Whether or not a conductive part exists in the lower crust of Central Japan, as has been demonstrated by RESEARCH GROUP FOR CRUSTAL RESISTIVITY StRUCTURE, JAPAN (1983) and OGAWA et al. (1985) beneath Northeast Japan.

3) Whether or not the upper mantle beneath the Japan Sea is really conductive. Conductivity structure beneath the sea floor depends on the age of the oceanic crust (FILlOUX, 1980), and may reveal how its opening had taken place in geologic time. Therefore, the structure can be important in the discussion of the opening of the Japan Sea.

\section{Data Analysis}

Observational sites for the present investigation are given in Table 1. Sites numbered from 1 to 17 are those of the cooperative project in 1982 by the Research Group for Crustal Resistivity Structure, Japan (YUKUTAKE, 1984). Sites with abbreviated names UCU, KMR and SRT are those for temporal measurements previously conducted, results of which were already reported partly by SASAI (1969), while YAT and SIM are permanent observatories belonging to the University of Tokyo and the MARITIME SAFETY AgEnCY (1981), respectively. Sea floor sites, named such as J6, are those for magnetic observation. JE1 and JE2 are sea floor sites for measurement of electric field variations, which are not analysed in this work.

At YAT and most of the 1982 sites, three component geomagnetic variations were simultaneously recorded every minute by fluxgate magnetometers with a resolution of $0.1 \mathrm{nT}$. Electric field variations were also recorded at many stations. However, the records were so severely contaminated by artificial noises mostly from electrical railways that only few of them were analysed. Data from OBM sites were also acquired in digital form with sampling rate of two or three minutes and resolution of 0.1 or $0.7 \mathrm{nT}$ (SEGAWA et al., 1982). Data at UCU, KMR, SRT and SIM, which were originally recorded on recording charts, were digitized at every 3 minutes.

From the compiled geomagnetic variation data, complex geomagnetic transfer functions $A(f)$ and $B(f)$ were calculated, which relate vertical component variation $Z(f)$ to those in horizontal component $H(f)$ and declination $D(f)$ in the frequency domain as follows,

$$
Z(f)=A(f) H(f)+B(f) D(f)
$$


Table 1. Location of observation sites.

\begin{tabular}{|c|c|c|c|c|c|c|}
\hline \multirow{2}{*}{$\frac{\text { Site }}{\text { No.01 }}$} & \multicolumn{2}{|c|}{ Latitude } & \multicolumn{2}{|c|}{ Longitude } & \multirow{2}{*}{$\frac{\text { Obs. year }}{1982}$} & Remark \\
\hline & 36 & 59.0 & 137 & 54.2 & & No data \\
\hline No. 02 & & 41.3 & 137 & 56.9 & 1982 & \\
\hline No. 03 & 36 & 5.3 & 137 & 41.1 & 1982 & \\
\hline $\mathrm{No} .04$ & 35 & 57.6 & 138 & 33.3 & 1982 & \\
\hline No. 05 & 35 & 34.5 & 1.38 & 3.8 & 1982 & \\
\hline No. 06 & 35 & 22.4 & 137 & 41.4 & 1982 & \\
\hline No. 07 & 35 & 21.2 & 137 & 57.4 & 1982 & \\
\hline No. 08 & 34 & 53.6 & 137 & 57.4 & 1982 & \\
\hline No. 09 & 35 & 25.3 & 138 & 35.2 & 1982 & \\
\hline No. 10 & 35 & 24.1 & 138 & 39.3 & 1982 & \\
\hline No. 11 & 35 & 16.3 & 138 & 38.0 & 1982 & \\
\hline No. 12 & 35 & 6.5 & 138 & 23.4 & 1984 & \\
\hline No. 13 & 35 & 0.1 & 137 & 55.2 & 1982 & \\
\hline No. 14 & 34 & 38.8 & 138 & 7.3 & 1982 & \\
\hline No. 15 & 34 & 36.4 & 138 & 13.3 & 1982 & \\
\hline No. 16 & 34 & 43.9 & 138 & 47.7 & 1982 & \\
\hline No. 17 & 36 & 16.7 & 137 & 26.9 & 1982 & \\
\hline YAT & 36 & 4.1 & 138 & 26.3 & 1982 & Observatory \\
\hline KMR & 36 & 19.0 & 138 & 27.5 & 1959 & \\
\hline SRT & 34 & 10.5 & 135 & 38.7 & 1967 & \\
\hline S IM & 33 & 34.5 & 135 & 55.5 & 1965 & \\
\hline $\mathrm{UCU}$ & 37 & 18.0 & 1.37 & 16.0 & 1965 & \\
\hline J 6 & 34 & 9.0 & 137 & 30.0 & 1983 & OBM site \\
\hline $\mathrm{J} 7$ & 33 & 43.0 & 137 & 37.0 & 1983 & oBM site \\
\hline J 8 & 33 & 14.0 & 137 & 30.0 & 1983 & OBM site \\
\hline J9 & 32 & 19.0 & 137 & 31.0 & 1983 & OBM site \\
\hline JE 1 & 33 & 59.0 & 137 & 27.0 & 1983 & OBE site \\
\hline J 12 & 32 & 47.0 & 136 & 34.0 & 1984 & OBM site \\
\hline J 13 & 32 & 13.0 & 137 & 20.0 & 1984 & OBM site \\
\hline J 14 & 31 & 38.0 & 136 & 12.0 & 1984 & OBM site \\
\hline $\mathrm{JE} 2$ & 32 & 5.0 & 137 & 3.0 & 1984 & OBE site \\
\hline
\end{tabular}

where $f$ is frequency. $A(f)$ and $B(f)$ were estimated at each station for several geomagnetic disturbances by using the spectral analysis method (EVERETT and HYNDMAN, 1967). Since transfer functions were determined in the least squares sense, 95\% confidence intervals were also calculated following BENDAT and PIERSOL (1971).

Durations of magnetic disturbances which were analysed here were about two days for the longest and twenty four hours for most of them, which enabled us to obtain reliable estimates of spectra at periods up to about 120 minutes. On the other hand, magnetic records were digitized at sampling intervals of less than 3 minutes that limited the shortest observable period as 6 minutes. Spectra of geomagnetic variations at several stations were found to be disturbed by noises from electrical railways at shorter periods, less than 10 minutes. Therefore, we had to elliminate these noises by using numerical high-cut filter beforehand. Finally, we selected period range between 120 and 15 minutes for the analysis.

\section{Distribution of Induction Vectors}

Overall distributions of the induction vectors in this area are shown in Figs. 1(a)-(d) for the periods of 15, 30,60 and 120 minutes, respectively, by using the complex transfer functions $A(f)$ and $B(f)$. As a general feature, most of the vectors 


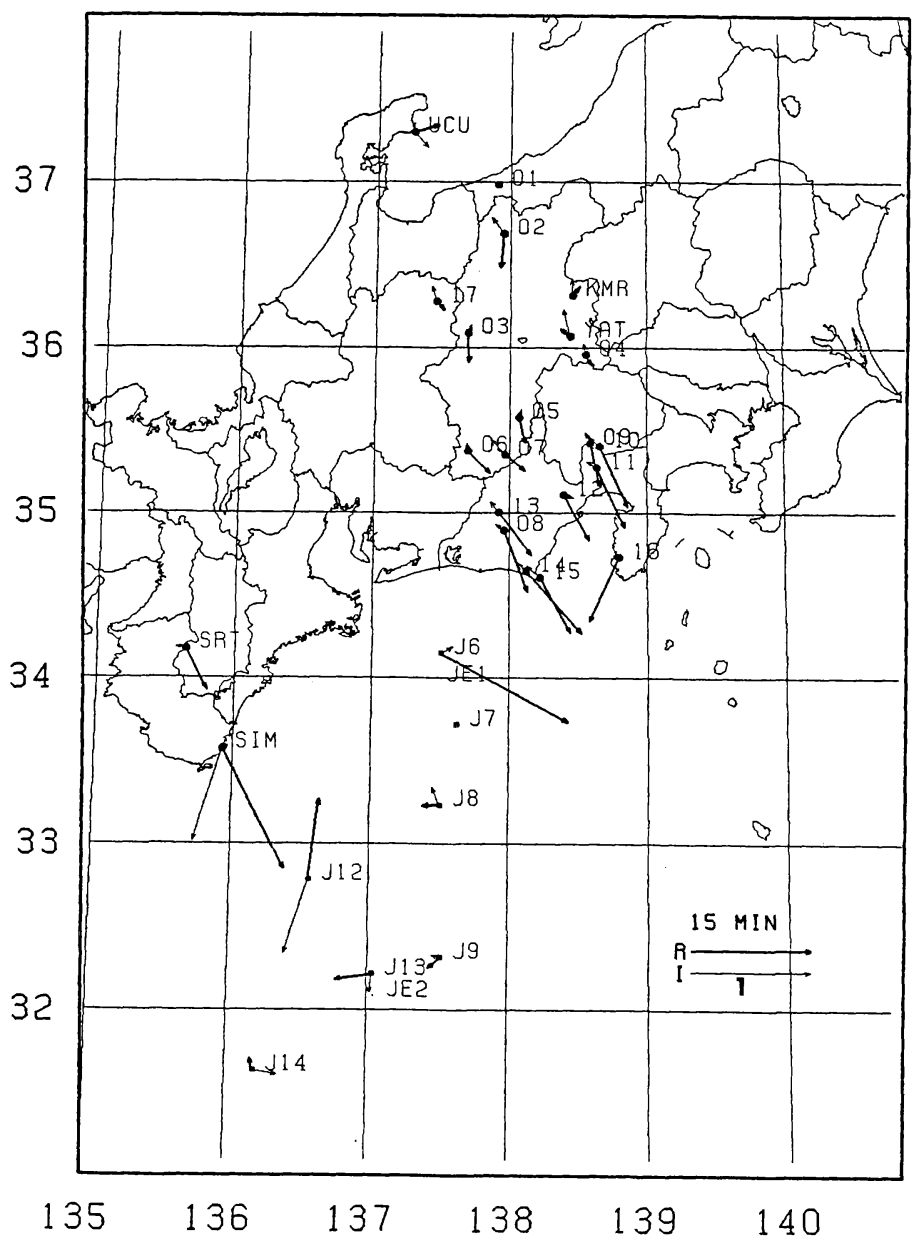

(a)

Fig. 1. Distributions of induction vectors at the period of 15(a), 30(b), 60(c) and 120 minutes(d). Real and imaginaly vectors are denoted by thick and thin arrows, respectively.

point to the south or the southeast, which is almost normal to the mean trend of the southern coastline. At the OBM sites far off the coast, the induction vectors are very small at shorter periods, while they become significantly large and point southward at longer periods. At the land sites near the southern coast, they point to almost the same direction, perpendicular to the coastline, and have nearly the same amplitudes. The vectors at No. 16 and SIM show quite different features; i.e. the former points southwest for all the periods, and the latter has anomalously large amplitude especially at shorter periods. These two particular features are due to the peninsula effect (SASAI, 1969; HONKURA, 1983). Similar effect can be seen in the behavior of the induction vector at UCU situated in the Noto Peninsula. Therefore, these data have not been used for the further model study. 


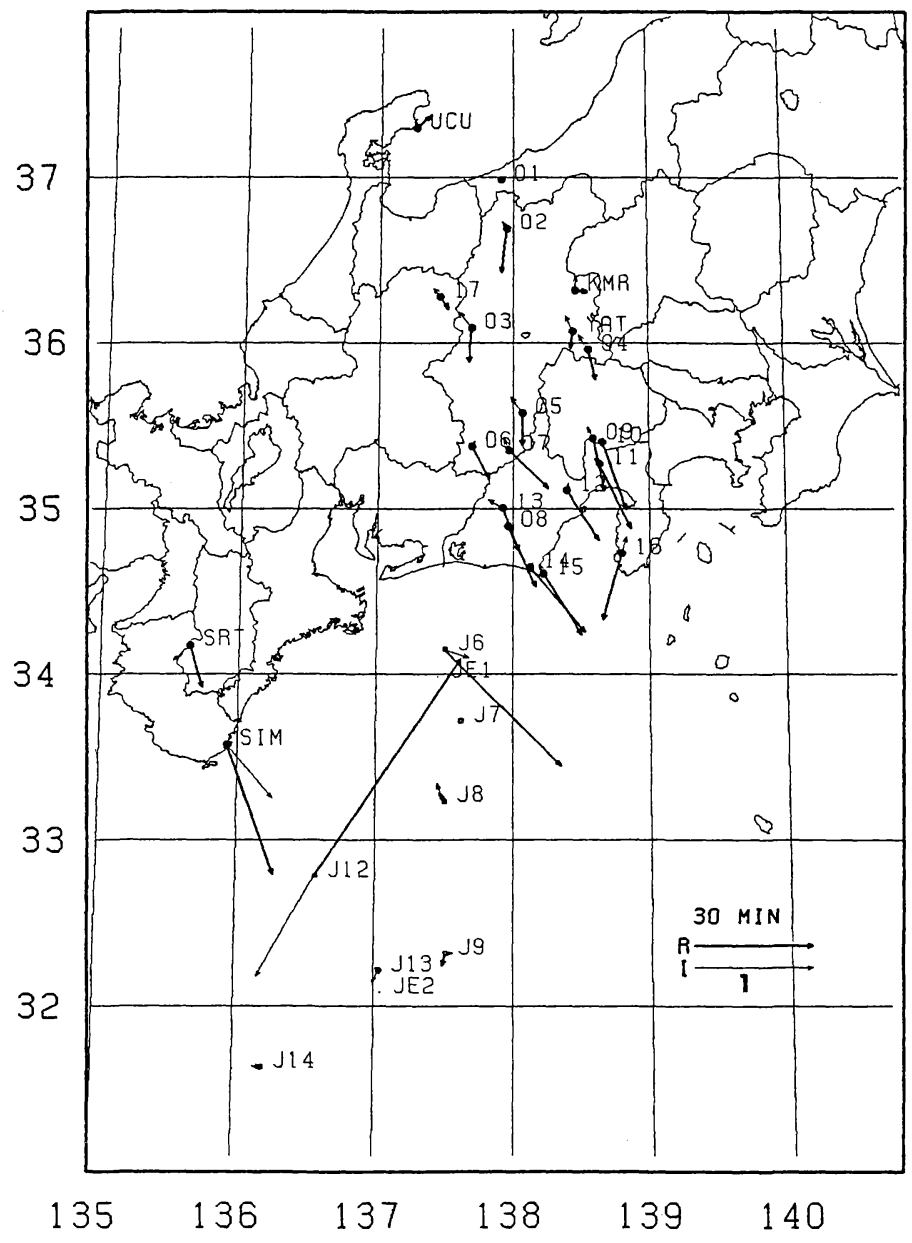

(b)

Length of induction vector at each frequency becomes shorter for the inland stations far from the Pacific coast. This implies that geomagnetic variations in this area are strongly affected by conductive sea water. It is striking that the vectors become small or change their directions northwards at YAT and KMR for shorter periods, while it still remains large and points southward at No. 02 which is situated farther north from the Pacific coastline and nearer to the Japan sea coast than YAT and KMR. This feature could not be explained by the coast effect only.

One may be cautious of queer behavior of the induction vector at the OBM site $\mathrm{J} 12$, whose direction is quite different from those at other sites, is nearly parallel to the coastline. It was found that the record of vertical component at this site was heavily contaminated by stepwise noises which were instrumental in nature. This anomalous behavior was due to instability in spectral estimates because of the noises, and hence the data at $\mathrm{J} 12$ were evaluated with less significance in further investigations. 


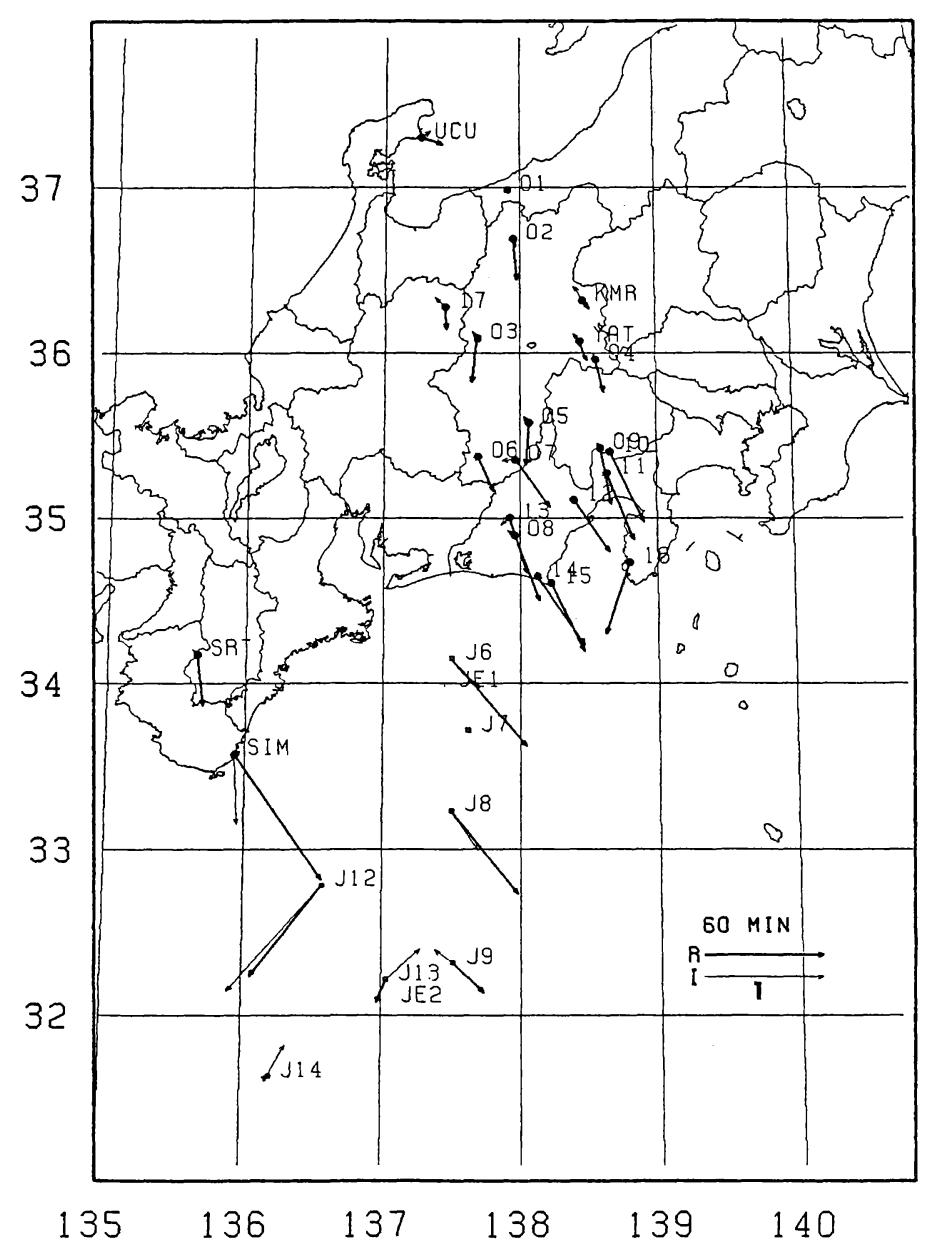

(c)

Fig. 1 (continued).

In view of similar directions of induction vectors, about 30 degrees east from south, we can reasonably assume a two-dimensional conductivity structure beneath this region. In order to determine the subterranean structure by comparing the observed transfer functions to those by theoretical calculations, we obtained twodimensional profiles of complex transfer functions by projecting the observed induction vectors onto the line parallel to N30W-S30E (Fig. 2). The projected transfer functions are shown in Figs. 3(a)-(d) at the periods of 15, 30, 60 and 120 minutes, respectively.

Since all the observed induction vectors do not strictly point to the projected direction, prescribed vector projection yields residual components which are perpendicular to the traverse. Here we call them residual transfer functions. Figure 4 shows profiles of the residual transfer functions at the period of 30 minutes in this area 


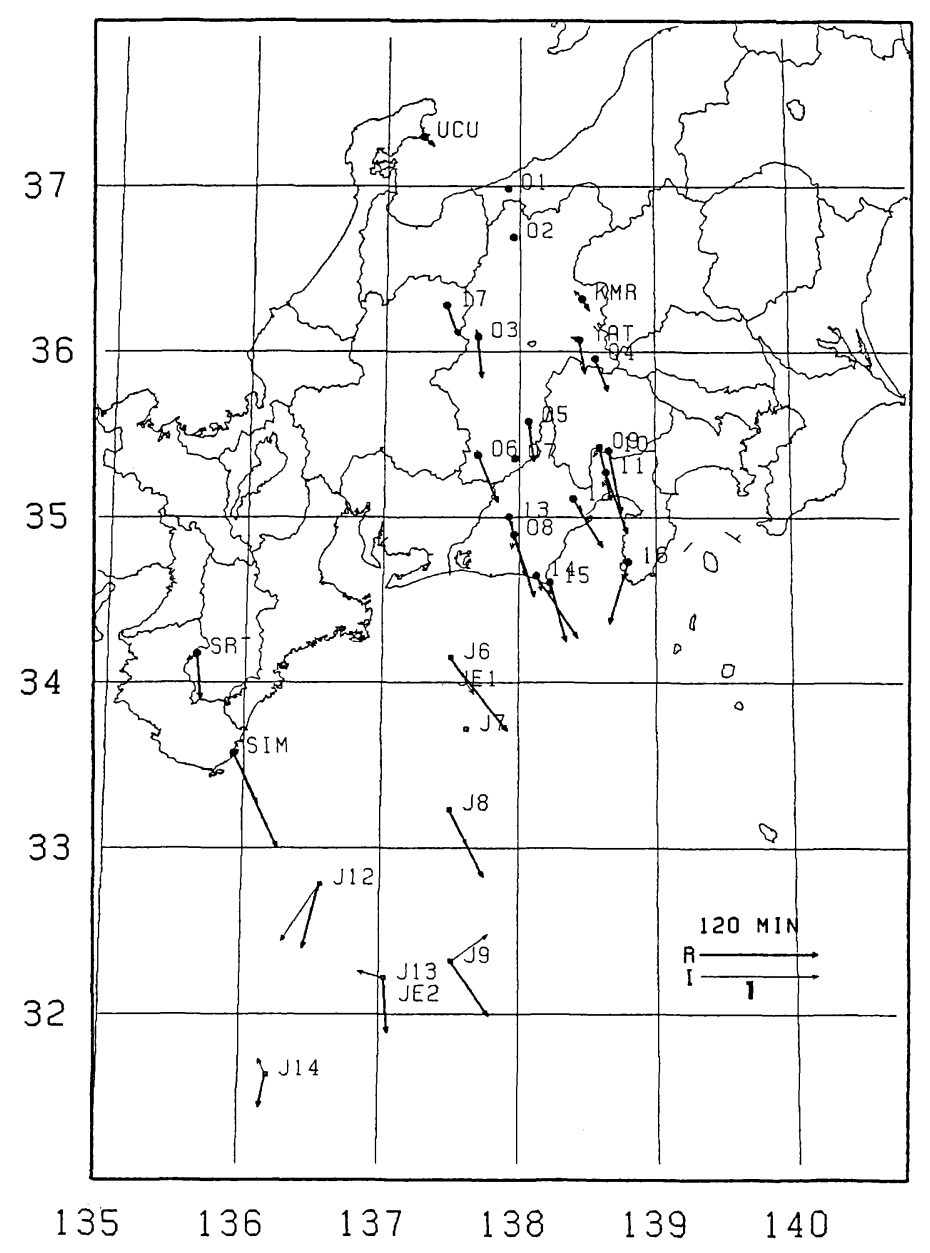

(d)

and those in Northeast Japan (OGAWA et al. 1985) along the east-west direction (Fig. 2). If the subterranean structure is nearly two-dimensional along the projected line, all induction vectors should point to the same direction, that is perpendicular to the structural trend, leaving the residual transfer functions to be null amplitude. The result shows that, in Central Japan, amplitudes of the residual transfer functions are sufficiently small compared with those of projected ones as shown in Fig. 3(b), even smaller than those in the Northeast Japan, where the subterranean structure is well approximated as two-dimensional. This fact supports the validity of the assumption of two-dimensional structure beneath this region. Of course, these residual transfer functions should contain some information about three-dimensionality of the subsurface structure. However, we will not discuss it any further here, because much denser distribution of observation sites is required for the discussion.

Now we pick up some prominent features of the projected transfer functions 


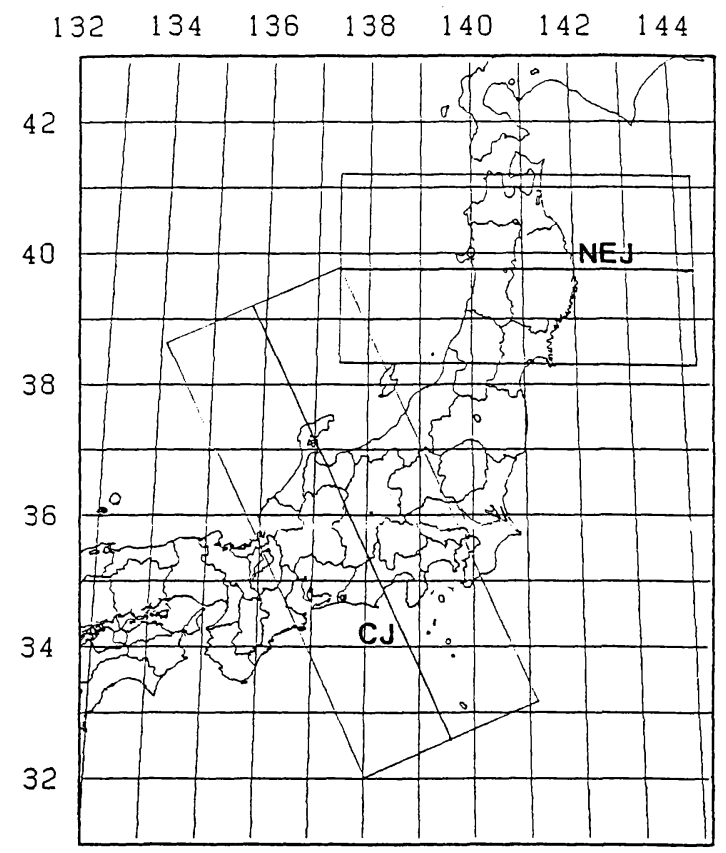

Fig. 2. Lines on which induction vectors are projected for Central Japan (CJ) in this work and for Northeast Japan (NEJ) by OGAWA et al. (1985).

shown in these figures. At sites between the Pacific coast and the Nankai Trough, the amplitude of transfer function is large, sometimes exceeding 1.0, presumably arising from the large conductivity contrast between the land and seawater. The phase varies on the sea floor differently for different periods, while it is almost zero at the Pacific coast. The rate of phase variation seems to become smoother for the longer periods. In contrast with a strong coast effect seen in the Pacific coast, the effect seems weak in the Japan sea side. The phase does not exceed -90 degrees even at the site No. 2 which is the nearest to the Japan Sea. This has already been discussed by HoNKURA (1974) and OGAWA et al. (1985).

In the middle of Central Japan, a striking feature is observed in spatial and period dependence of phase: from the south to the north, the phase for the period of 15 minutes once decreases down to about -120 degrees at YAT and KMR, then turns to increase at sites No. 02 and No. 17. Similar tendency can be seen at longer periods though less remarkable. Since the spatial scale of the anomalous phase variation is as small as about $50-70 \mathrm{~km}$ and it is conspicuous at the shorter periods, this anomaly can be attributed to a rather shallow conductor, possibly in the crust.

\section{Magnetotelluric Results}

Sometimes surface sedimentary layers cause significant geomagnetic variation anomalies (PORATH and DzIEWONSKI, 1971). Therefore, it is very important and helpful to know conductivity distribution at shallower depth even when one wants to 
investigate the deep conductivity structure. We conducted magnetotelluric measurements in the ELF and VLF ranges at each one of the 1982 sites. For ELF range, electric and magnetic fields were recorded simultaneously, and then complex tensor impedances were determined at the frequencies of three fundamental modes of the Schumann resonance. Apparent resistivity and phase difference between electric and magnetic field variations were also measured for the VLF range by use of an EM1616R system of Geonics at the frequency of $17.4 \mathrm{kHz}$ from NDT, Japan.

Figures 5(a) and (b) show the distributions of the apparent resistivity and the phase difference at the frequencies $17.4 \mathrm{kHz}$ and $8 \mathrm{~Hz}$, respectively. Striking resistivity contrast is seen between the central mountain and the coastal areas. For example, 2 $\mathrm{k} \Omega \cdot \mathrm{m}$ and $3 \mathrm{k} \Omega \cdot \mathrm{m}$ were obtained at No. 06 for VLF and ELF apparent resistivities, respectively, while both of them were less than $10 \Omega \cdot \mathrm{m}$ at No. 14 on the Pacific coast. These maps were used in determining the shallow conductivity values in the model calculation studies in the following section.

For longer periods such as about 30 seconds for geomagnetic micropulsations and several tens of minutes for substorm-like geomagnetic disturbances, electric field records were severely affected by noises mostly due to electric railways. Because of this situation, we could not obtain reliable estimates of magnetotelluric impedance for these period ranges except for one site, No. 3, which is situated on the southeastern foot of Volcano Norikura in the midst of the Hida mountain area. Using all the results ranging from VLF to the period of several tens of minutes, one-dimensional structure was inferred inversely (Fig. 6) using a five-layer model (YUKUTAKE, 1984). Beneath relatively conductive surface layers, a resistive upper crust exists down to the depth of about $20 \mathrm{~km}$. Then resistivity decreases by more than 3 orders of magnitude. A thin conductive layer is suggested at this depth. However, its existence can not be regarded as firmly established when the confidence intervals for the layer thickness are considered. Nevertheless, the fifth layer underlying this conductive layer is more conductive, with resistivity of about $100 \Omega \cdot \mathrm{m}$, than the third resistive layer. The conductive layer should be located within the crust, since the MOHO depth is deeper than $30 \mathrm{~km}$ in this area, implying that the lower crust is conductive. It remains uncertain from a magnetotelluric result at the single station whether this conductive lower crust reflects a general feature of the crustal structure beneath this region or only a local one.

\section{Two-Dimensional Model by the Finite Element Method}

In order to investigate how the observed responses can be explained by a two-dimensional structure, modeling has been carried out by using a finite element method (REDDY and RANKIN, 1975; OGAWA et al., 1985). The geomagnetic transfer function has been analysed as a response function, which is equivalent to examining E-polarization induction; in this case the electric field varies in parallel with the trend of structure.

The model covers the area between $950 \mathrm{~km}$ away from the Pacific coast and 700 $\mathrm{km}$ from the Japan sea coast horizontally, from $150 \mathrm{~km}$ above sea level down to 1,500 $\mathrm{km}$ depth vertically, with the total area being $1,900 \mathrm{~km} \times 1,650 \mathrm{~km}$. In this way boundaries have been taken far enough so that boundary conditions are unlikely to affect responses for the areas under consideration. 


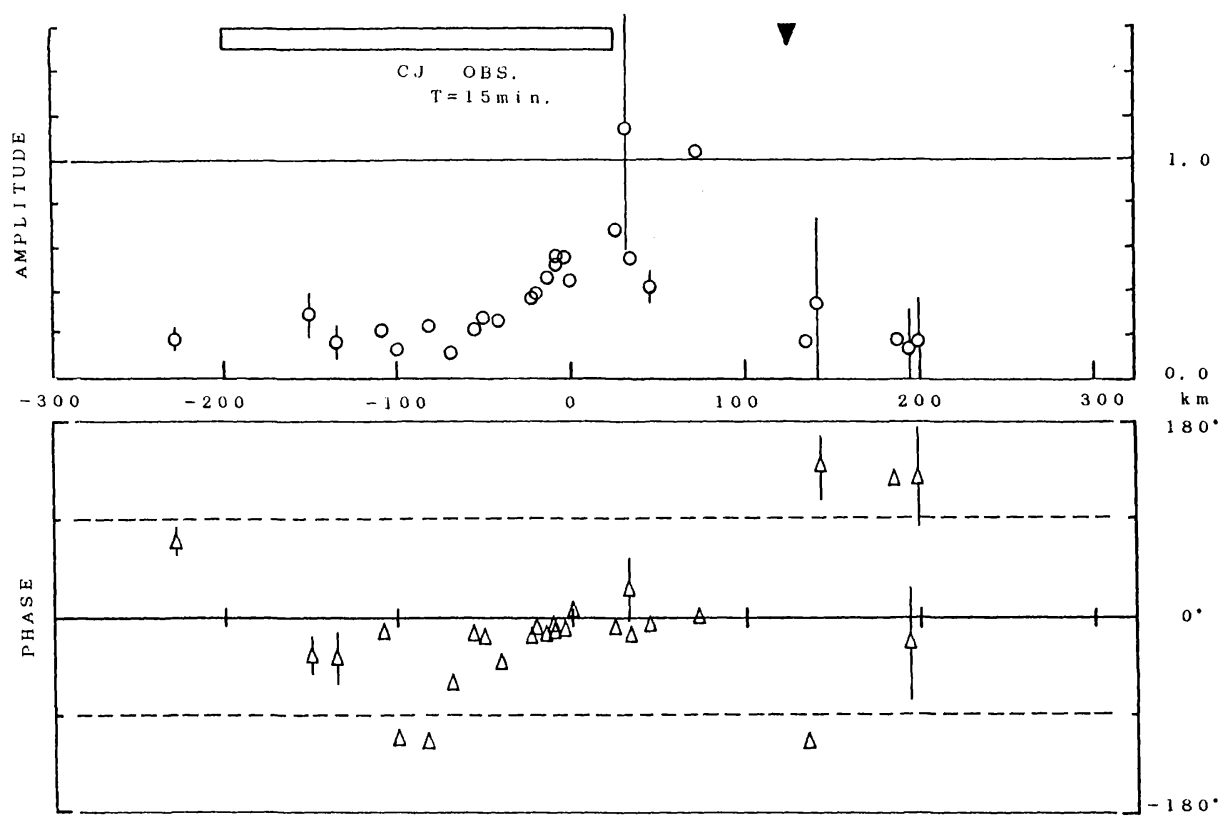

(a)

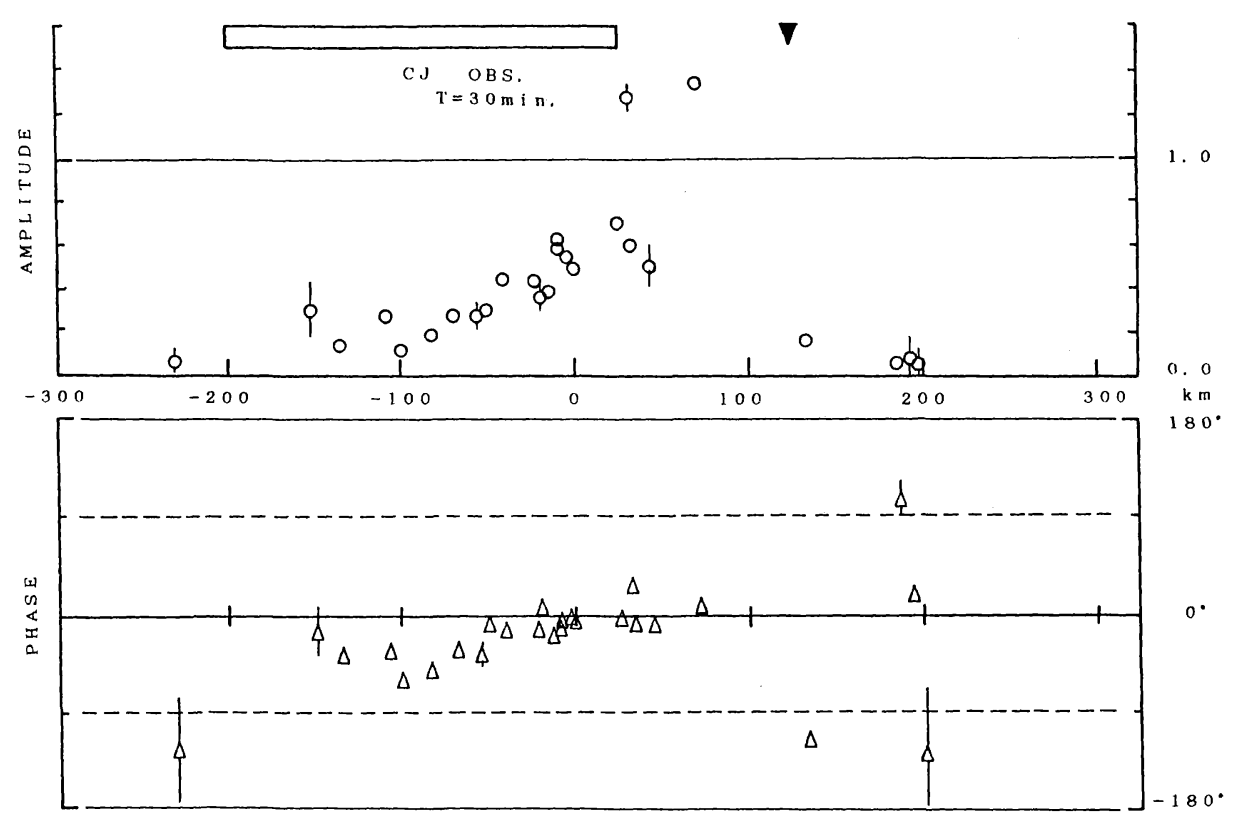

(b)

Fig. 3. Profiles of amplitude (above) and phase (below) of the observed transfer functions along the line parallel to N30W-S30E for the period of $15(\mathrm{a}), 30(\mathrm{~b}), 60(\mathrm{c})$ and 120 minutes(d), respectively. 


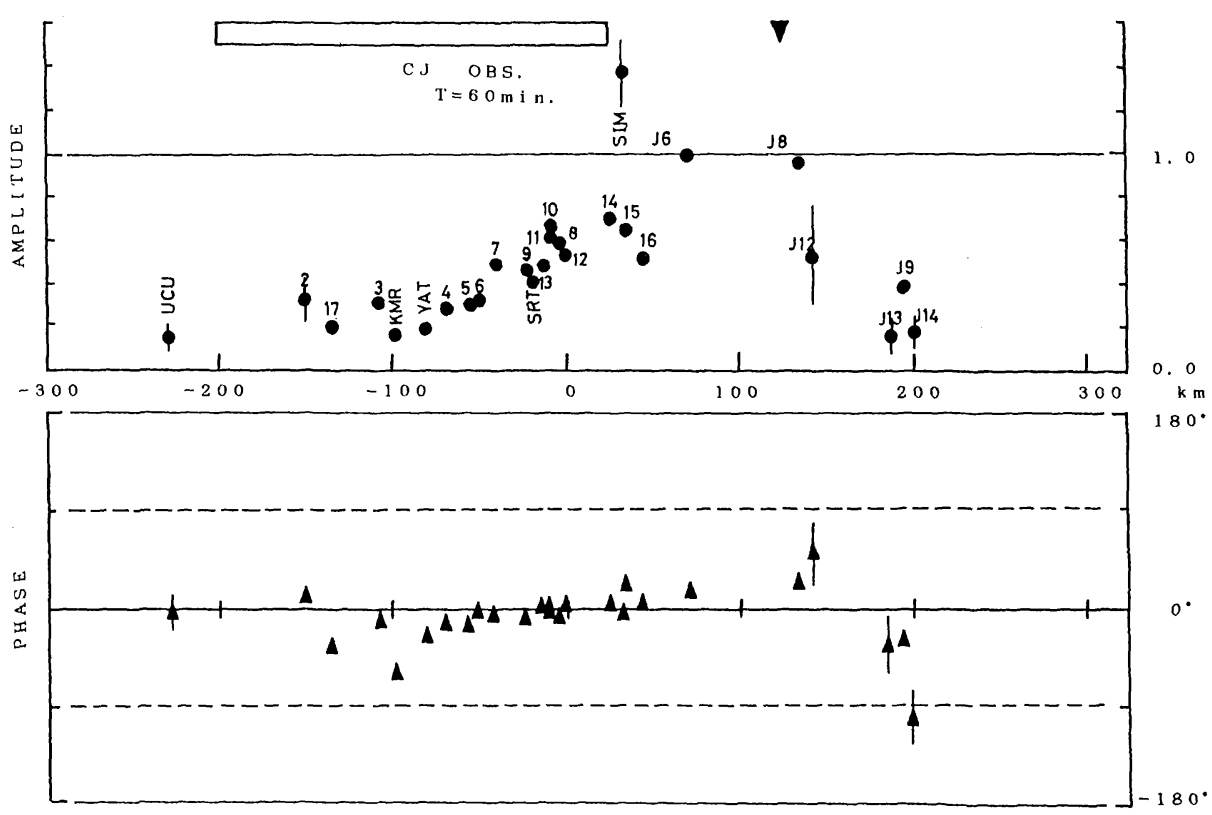

(c)

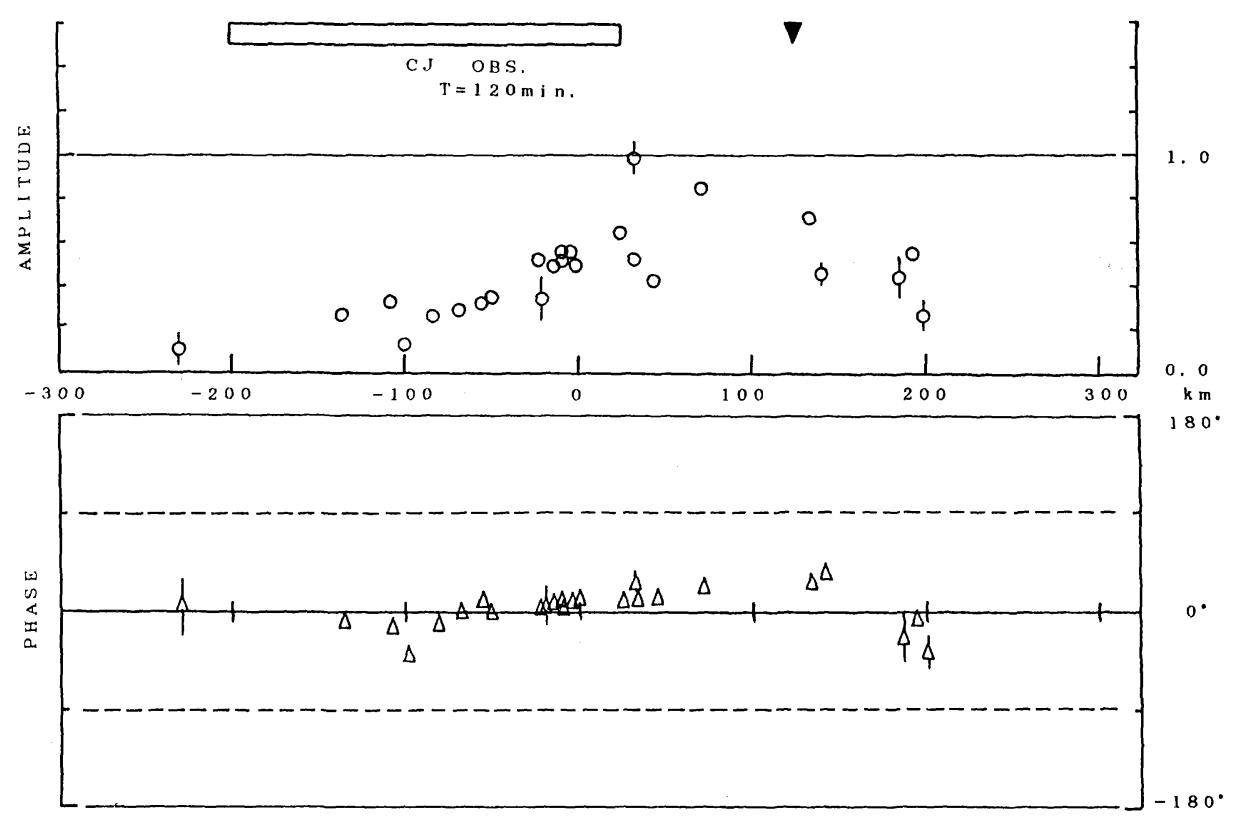

(d) 

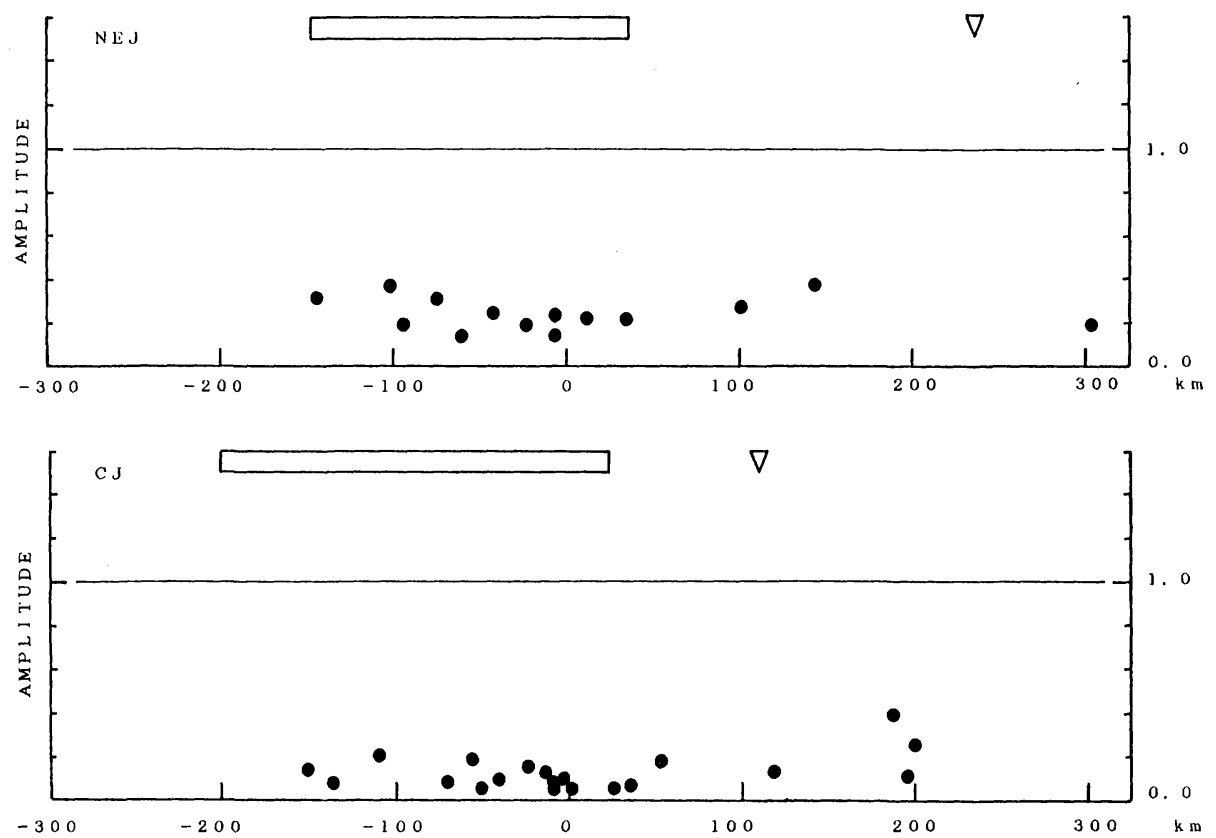

Fig. 4. Profiles of amplitude of the residual transfer functions at the period 30 minutes for Northeast Japan (above) and Central Japan (below). Triangles denote the Japan Trench for NEJ and the Nankai Trough for CJ, respectively.

The whole space was divided into 1080 triangular elements, whose sizes were carefully chosen to be sufficiently small compared with the inductive scale length of the field in each element. For example, vertical sizes of the near surface elements were taken as $100 \mathrm{~m}$ for the smallest ones because the skin depth for the electromagnetic field variation of 15 minutes period is as shallow as about $7.5 \mathrm{~km}$ in seawater whose conductivity is $5 \mathrm{~S} / \mathrm{m}$ or so. On the coast and continental shelf, the amplitude of electromagnetic variation changes sharply also in the horizontal direction because of the large conductivity contrast between the land and the sea. Hence, we adopted $5 \mathrm{~km}$ as the horizontal scale of the elements in this area.

Since we attempt to investigate the subterranean conductivity structure by using the transfer function or the ratio $Z(f) / H(f)$ as a response function, the fundamental equation we must solve becomes, assuming $\partial / \partial x=0$,

$$
\left(\partial^{2} / \partial y^{2}+\partial^{2} / \partial z^{2}-k^{2}\right) E x=0,
$$

where $k^{2}=-i \omega \mu \sigma$,

$\omega, \mu$ and $\sigma$ are the angular frequency, the magnetic permeability and the conductivity of the medium, respectively. Magnetic field variations $\mathrm{Hy}$ and $\mathrm{Hz}$ can be obtained by taking the spatial derivatives of the electric field as follows;

$$
H y=1 /(i \omega \mu) \quad \partial E x / \partial z,
$$




$$
H z=-1 /(i \omega \mu) \quad \partial E x / \partial y
$$

Two different kinds of boundary condition were applied to solve the fundamental equation (Eq. 2). One is natural boundary condition, which was employed for the side and the bottom boundaries,

$$
\partial E x / \partial n=0
$$

where $\partial / \partial n$ denotes the derivative with respect to the direction normal to the boundary. This means that, outside of these boundaries, the electric field does not change towards the direction perpendicular to them. In other words, the vertical component of magnetic variation vanishes beyond the side boundaries, while null amplitude of the horizontal component is assumed below the bottom boundary. On the other hand, electric field intensity was taken to be unity at each nodes on the top boundary. This means that the vertical magnetic field is assumed to vanish on the top boundary. As has been previously mentioned, these boundaries were made sufficiently distant from the area of the present investigation to minimize the boundary effect.

We began modeling with incorporation of the surface structures so far known along the profile into the model, particularly the following features which were obtained from geology and magnetotelluric results (Fig. 7);

1) Conductive sea water of the Philippine and Japan Seas. Sea floor topographies were carefully read along the profile from the bathymetric chart.

2) Thick sedimentary layer on the sea floor and continental shelf, whose conductivity was taken to be $0.1 \mathrm{~S} / \mathrm{m}$.

3) Tertiary or Quaternary sediments or sedimentary rocks in the coastal areas. The conductivity was estimated as $0.5 \mathrm{~S} / \mathrm{m}$ for the Philippine Sea side, while $0.1 \mathrm{~S} / \mathrm{m}$ was applied for the Japan Sea coast, on the basis of the magnetotelluric results as mentioned above.

4) Outcrops of resistive rocks, as resistive as $0.001 \mathrm{~S} / \mathrm{m}$, in the areas north of the Median Techtonic Line.

5) Result of magnetotelluric sounding at No. 03 site suggests the conductivity of the upper crust beneath Central Japan to be $10^{-3}-10^{-4} \mathrm{~S} / \mathrm{m}$. A simialr value has been assigned to the oceanic plates in the previous studies (e.g., FILlouX, 1980, 1981). We applied $10^{-3} \mathrm{~S} / \mathrm{m}$ for the conductivity of the oceanic crust and the upper crust beneath Central Japan.

Parameters of the structure deeper than prescribed above were left to be determined in future.

\section{Model Results}

In constructing a reasonable model beneath Central Japan, we have fixed the surface conductivity structure, down to $4 \mathrm{~km}$, as has been shown in the previous section. Then, we first calculated the theoretical responses for the model in which uniform conductivity of $0.001 \mathrm{~S} / \mathrm{m}$ was assumed except for the fixed surface structure. We used this model as a starting model to obtain more realistic models. Several discrepancies were found between the observed responses and the calculated ones, as shown in Fig. 8 which shows one of the results for the period of 15 minutes. 


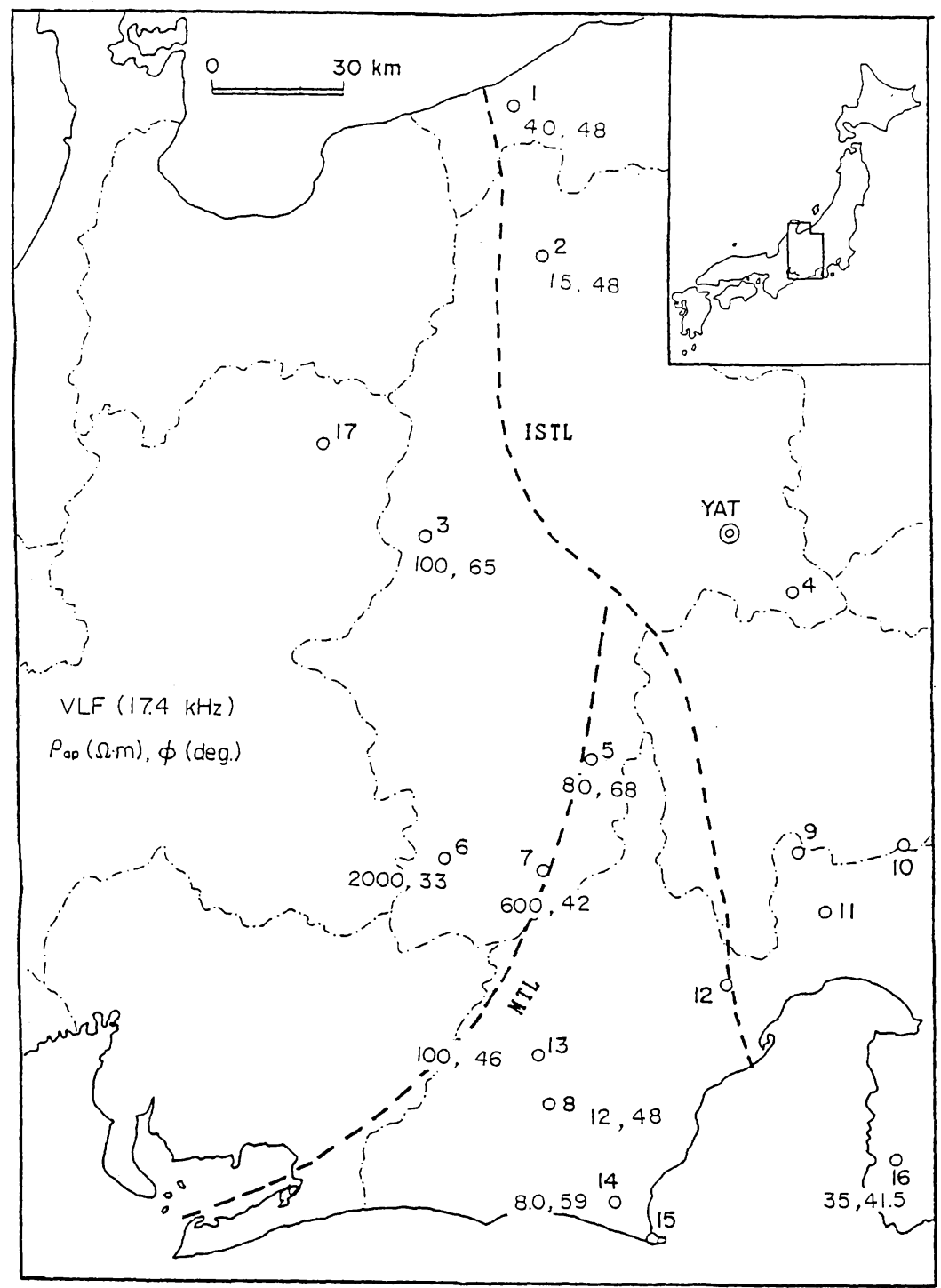

(a)

Fig. 5. (a) Distribution of VLF apparent resistivity and phase at 1982 observation sites at the frequency of $17.4 \mathrm{kHz}$. MTL and ISTL denote the Median Tectonic Line and the Itoigawa-Shizuoka Tectonic Line, respectively. (b) Distribution of ELF apparent resistivity and phase calculated from the offdiagonal elements of impedance tensor at 1982 observation sites at the frequency of $8 \mathrm{~Hz}$.

For example, the calculated amplitude is larger than the observed one on the Philippine Sea floor and the calculated phase behaves quite differently in the central Japan area. It is obvious that additional conductivity inhomogeneities are required in order to explain these features. 


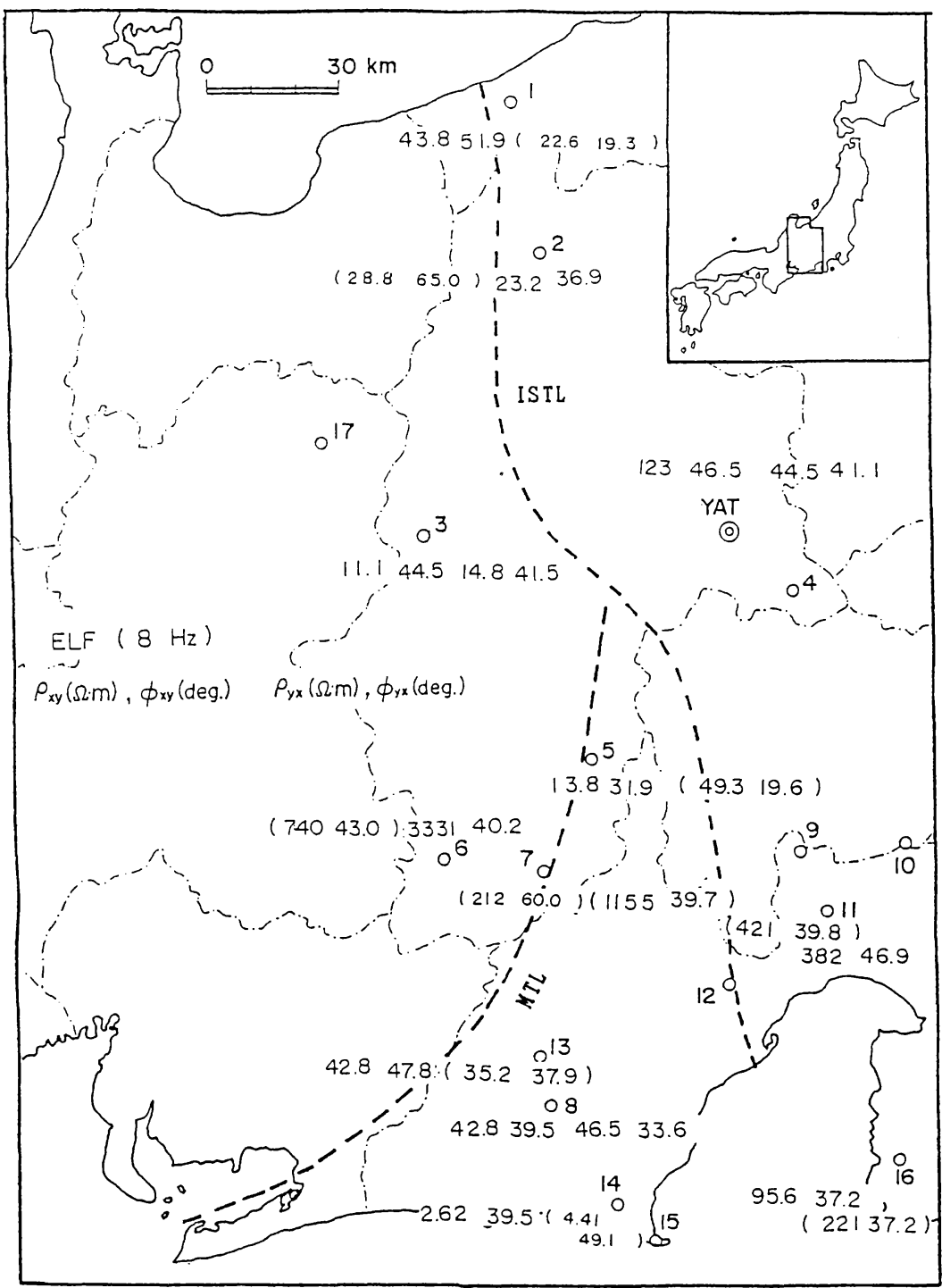

(b)

After several trials, we constructed our final model by introducing conductive bodies, whose conductivities are both as high as $0.1 \mathrm{~S} / \mathrm{m}$, beneath the Philippine Sea and Central Japan, as illustrated in Fig. 9. The resulting responses represent typical features, mentioned in Section 3, in the spatial characteristics for the whole period range as shown in Figs. 10(a)-(d).

The conductor beneath the Philippine Sea floor was introduced in order to suppress the large amplitudes of $Z / H$ in the starting model and to fit the phase variations on the sea floor sites in the vicinity of the Nankai Trough. Because of the 

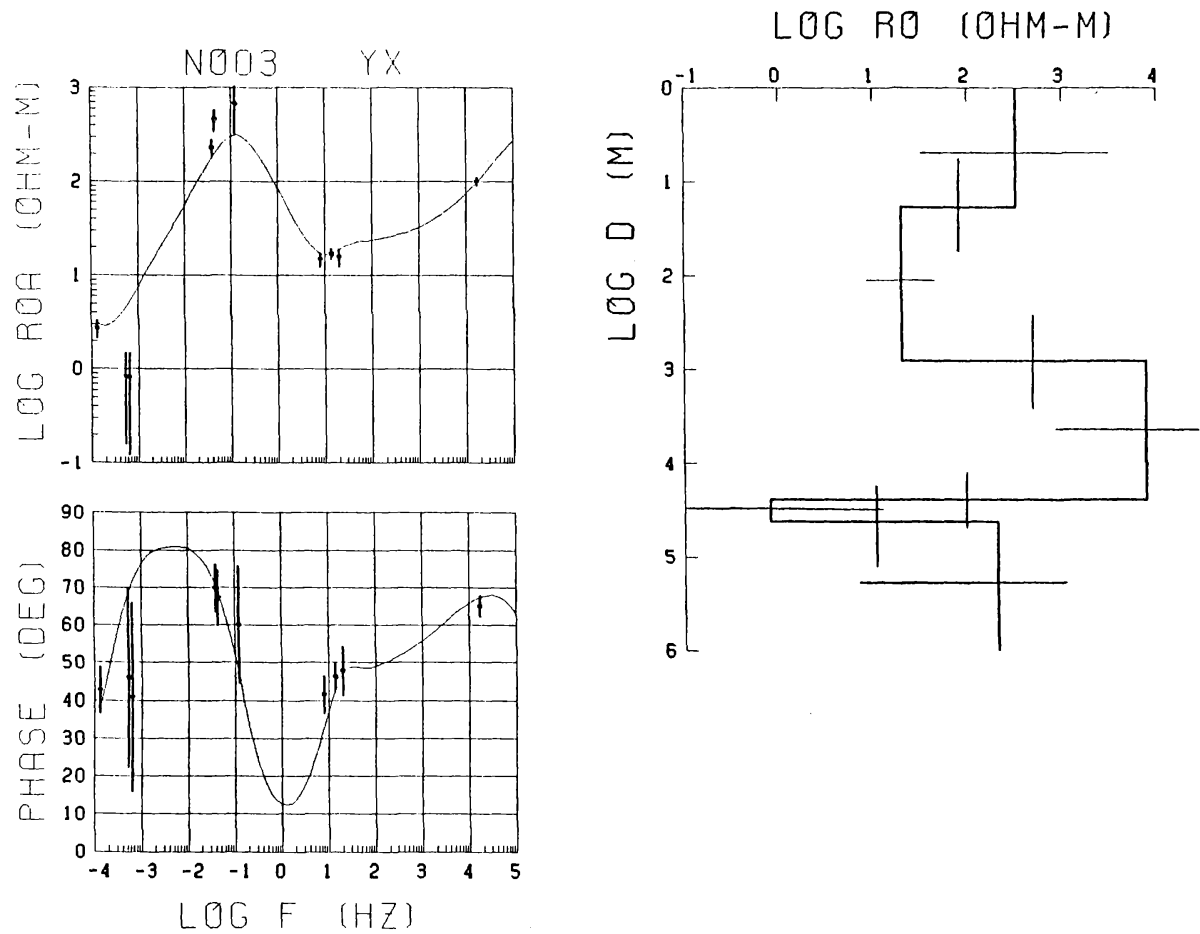

Fig. 6. Result of one-dimensional magnetotelluric inversion at the site No. 3. The left figure shows the fitness between the observations and the theoretical curve for the optimum model. The right figure gives the optimum structure with confidence intervals in estimated layer parameters (thickness and resistivity).

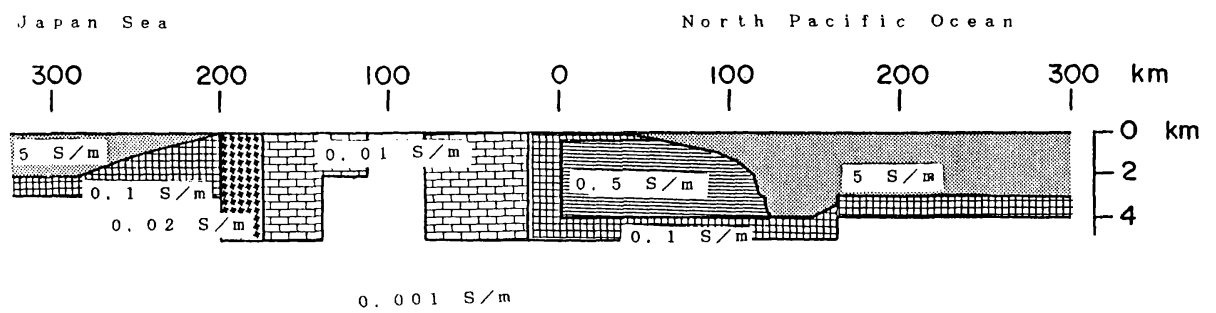

Fig. 7. Surface conductivity structure determined on the basis of VLF and ELF magnetotelluric results. Conductivity of the sea water is taken as $5 \mathrm{~S} / \mathrm{m}$. Sea floor topography was read from the bathymetric chart.

great conductivity contrast between land and seawater, $Z / H$ values would be several times larger at these sites without the deeper conductor (see Fig. 8). The depth to the top of this conductive layer, which was estimated as $30 \mathrm{~km}$ in our final model (Fig. 9), is an important parameter about the lithospheric structure of the Philippine Sea plate, because the conductive layer is considered to correspond to the top of the 

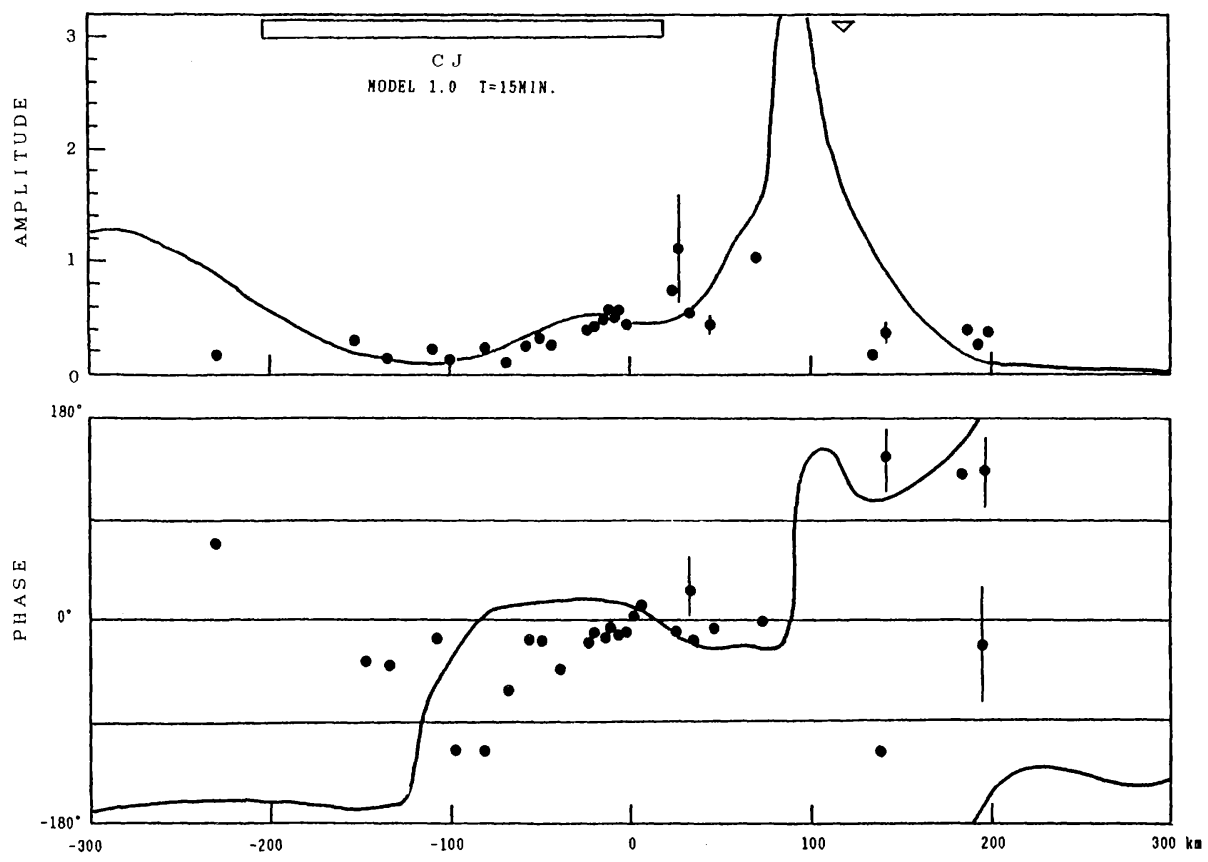

Fig. 8. Calculated profiles of amplitude (above) and phase (below) at the period of 15 minutes for the model where uniform subsurface conductivity of $0.001 \mathrm{~S} / \mathrm{m}$ is assumed except the fixed surface structure given in Fig. 7. Observed responses are denoted by dots. Large triangle indicates the axis of the Nankai Trough.

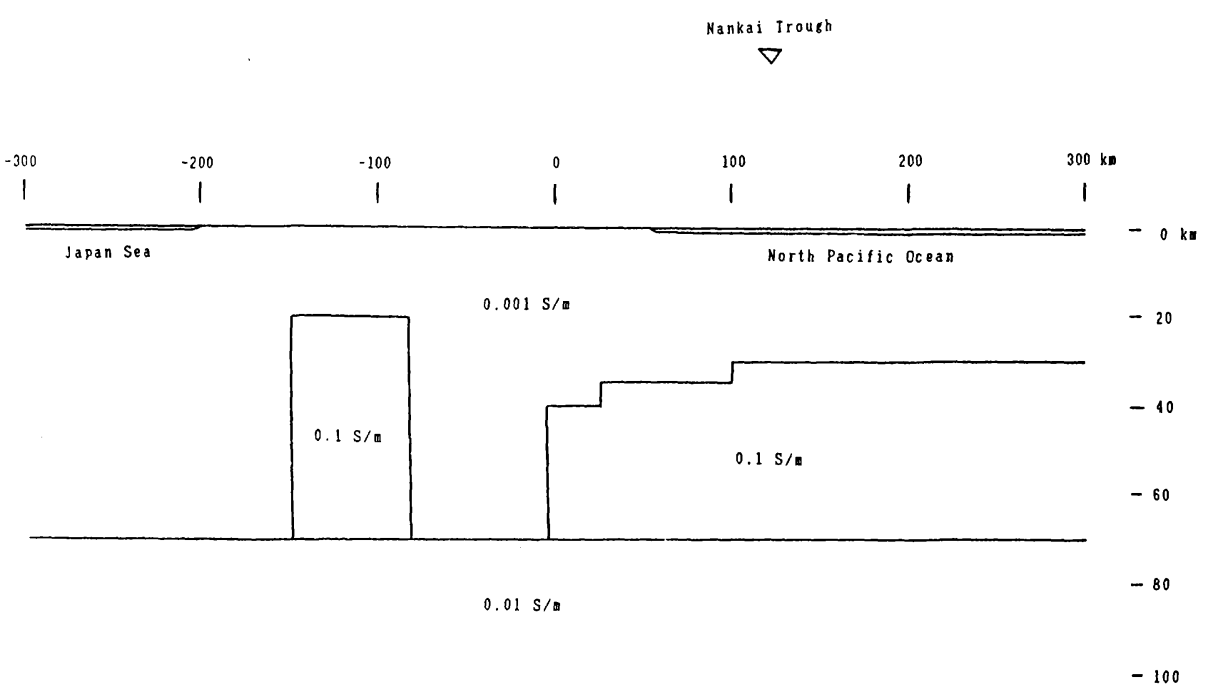

Fig. 9. Final two-dimensional conductivity structure. Surface distribution of conductivity is the same as given in Fig. 7. 

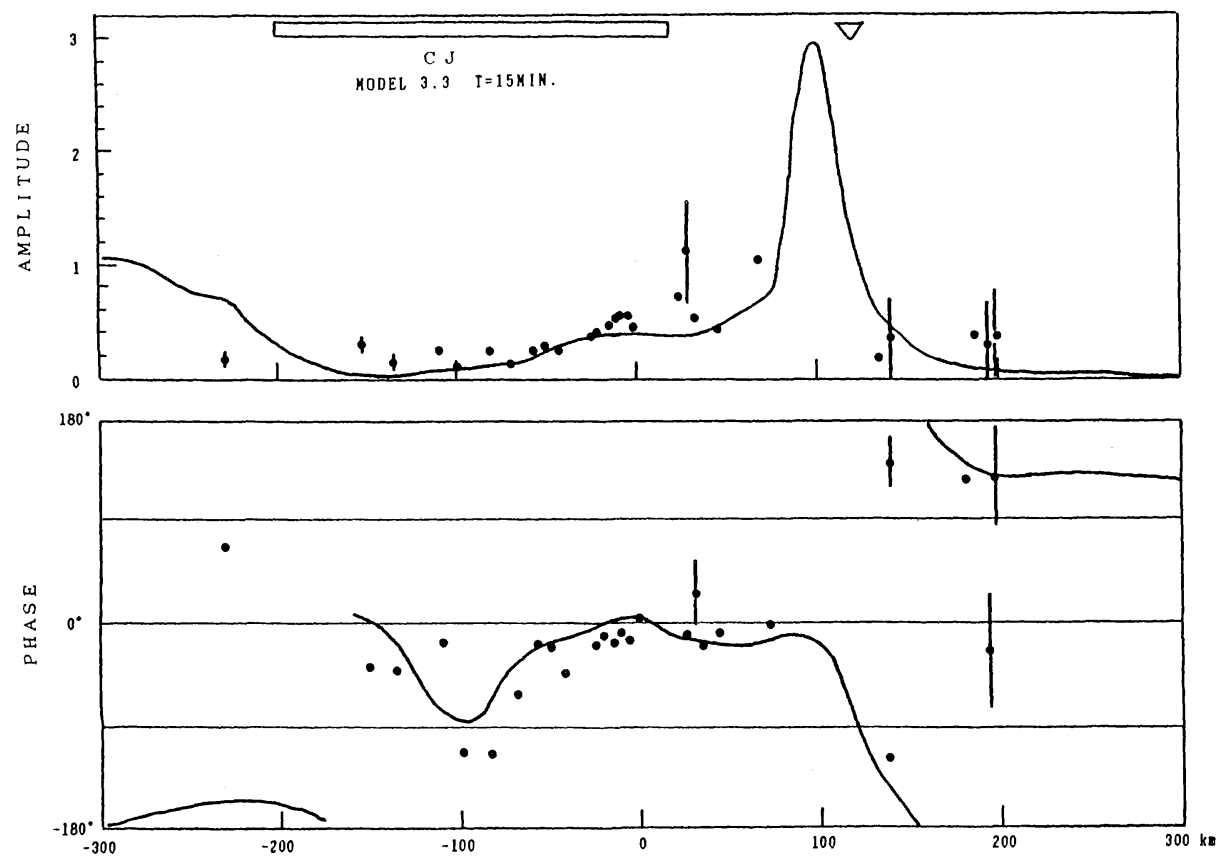

(a)
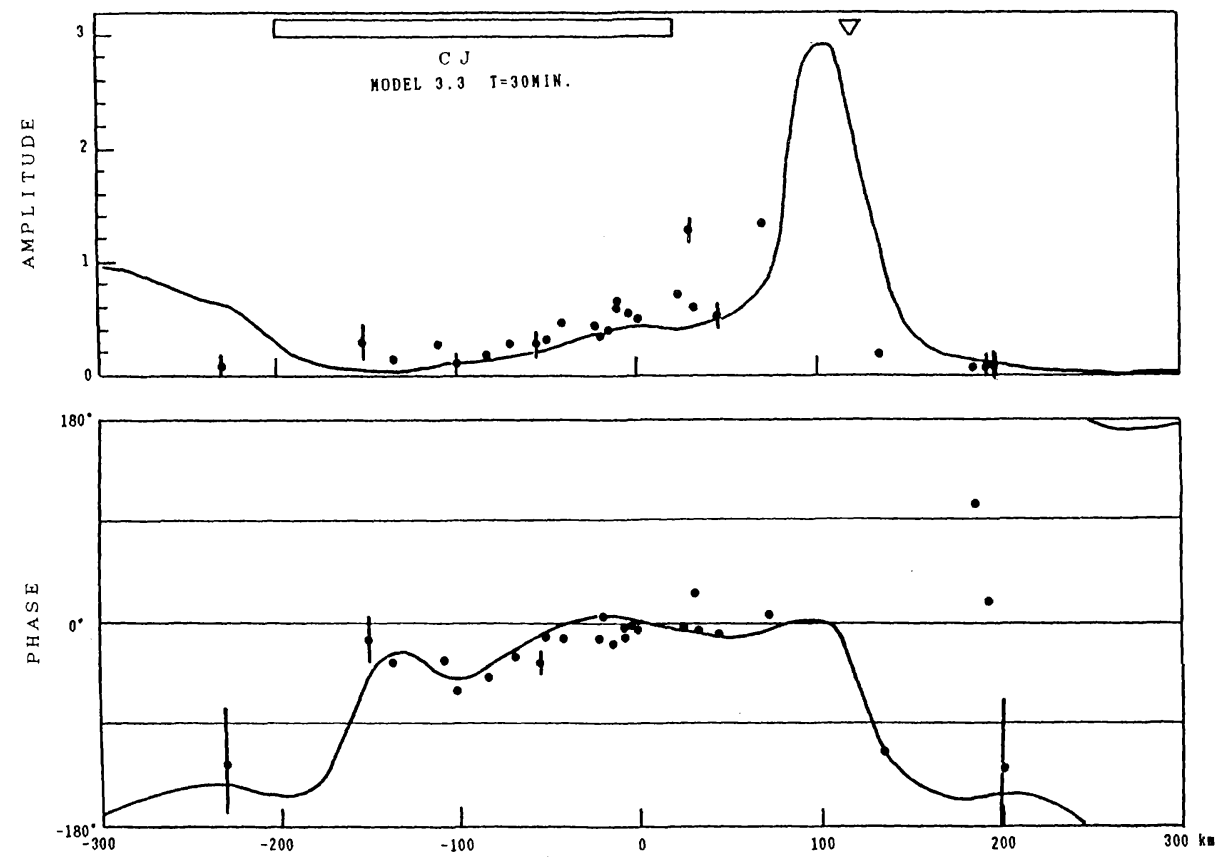

(b)

Fig. 10. Calculated responses for the final model. Solid lines show the calculated amplitude (above) and the phase (below) profiles at the frequencies of $15(\mathrm{a}), 30(\mathrm{~b}), 60(\mathrm{c})$ and 120 minutes(d), respectively. Dots denote observed responses. 

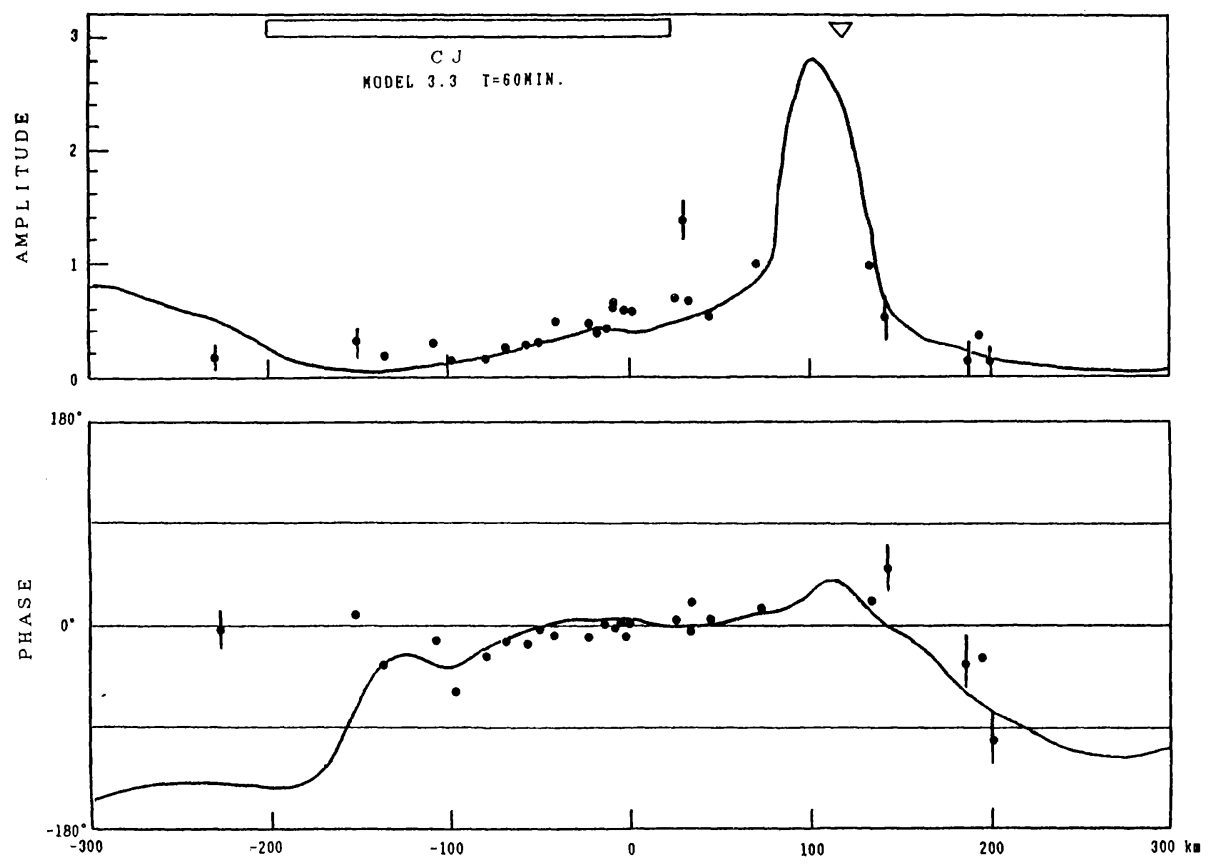

(c)
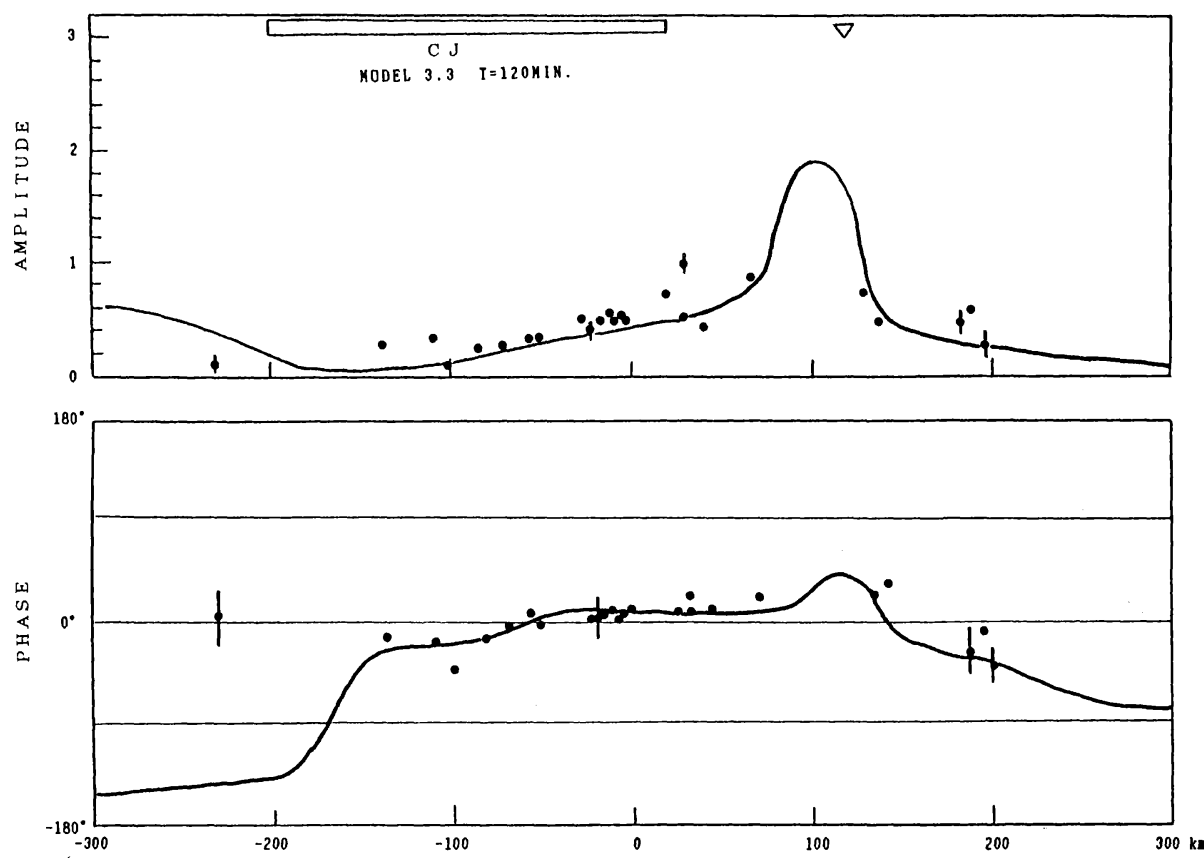

(d) 
asthenosphere (FILlOUX, 1980; OLDENBURG, 1981). Seismically, the depth to the low velocity layer beneath this area was estimated as $30 \mathrm{~km}$ by KANAMORI and ABE (1968) by using surface waves. Figures $11(\mathrm{a})$ and (b) give the sensitivity in determining the depth, $Z_{2}$, by comparing the responses for the final model with those for $Z_{2}=15$ and 50 $\mathrm{km}$, for the period of 15 and 120 minutes. At the period of 15 minutes (Fig. 11(a)), model responses shown by solid lines in both cases of $Z_{2}=15$ and $50 \mathrm{~km}$ differ significantly from those for the final model $\left(Z_{2}=30 \mathrm{~km}\right)$ shown by dashed lines, especially on the continental shelf. However, for the period of 120 minutes (Fig. 11(b)), little difference can be seen except for the portion very close to the trough axis where no observational data exist yet. We also made a calculation for $Z_{2}=20 \mathrm{~km}$, resulting in similar characteristics as those for $Z_{2}=30 \mathrm{~km}$. These figures suggest that we could determine the depth more precisely if much detailed measurements were made on the continental shelf close to the trough axis.

The conductor in the lower crust beneath Central Japan has never been seen in any of the previous investigations. It is perhaps because no geomagnetic variation data had been obtained except at KMR and YAT before the 1982 project. At both sites, the phase of $Z / H$ decreases down to about -120 degrees at shorter periods. This behavior of phase variation may be taken as the beginning of the coast effect by the Japan Sea. However, detailed measurements have indicated that the phase increases again to nearly 0 degree towards the coast. This requires an additional conductor in the lower crust beneath Central Japan.

Horizontal extension of this conductor can be determined very strictly because of a relatively short site spacings; between $120 \mathrm{~km}$ from the Pacific coast and $60 \mathrm{~km}$ from the Japan Sea coast (between -80 and $-160 \mathrm{~km}$ in the present scale of the figures). The sensitivity in determining the depth to it, $Z_{1}$, was examined in a similar way to the case of $Z_{2}$. Figures 12(a) and (b) show how the model responses are dependent on various values of $Z_{1}$ for the periods of 15 and 120 minutes, respectively. Acceptable values of $Z_{1}$ were found to be less than $20 \mathrm{~km}$, because the resulting phase at 15 minutes varies little for the case of $Z_{1}=30 \mathrm{~km}$. It is possibly greater than $10 \mathrm{~km}$ since the phase at 15 minutes changes too sharply for $Z_{1}=10 \mathrm{~km}$.

Beneath the Japan Sea floor, resistive upper mantle was assumed in our final model, although previous works had given conductive one. We have also examined the possibility of the latter too, but the resulting responses showed much poorer fit to the data. Figures 13(a) and (b) show the effect of the conductor beneath the Japan $\mathrm{Sea}$, if it exists at the depth of $30 \mathrm{~km}$ with the conductivity of $0.1 \mathrm{~S} / \mathrm{m}$, by varying the distance from the coast to it, $W$, at the periods of 15 and 120 minutes. Taking into account that the continental shelf in this area is extending as far as $100 \mathrm{~km}$ away from the coast, these figures indicate that the conductor must be at least $100 \mathrm{~km}$ away from the shelf break. If the edge of the conductor exists just beneath the shelf break ( $W=100 \mathrm{~km}$ ), another model result suggests that the conductor should be deeper than $50 \mathrm{~km}$.

We are now conscious of the role of both edges of the crustal conductor beneath Central Japan in the geomagnetic induction process; i.e. the southeastern edge causes a decrease in the phase of $Z / H$ at those sites situated between $-50 \mathrm{~km}$ and $-100 \mathrm{~km}$ at shorter periods, while the northwestern one makes an increase in the phase, in other words, suppresses the coast effect by the Japan Sea, at those sites between $-120 \mathrm{~km}$ and $-160 \mathrm{~km}$. The presence of upper mantle conductor beneath the Japan Sea 

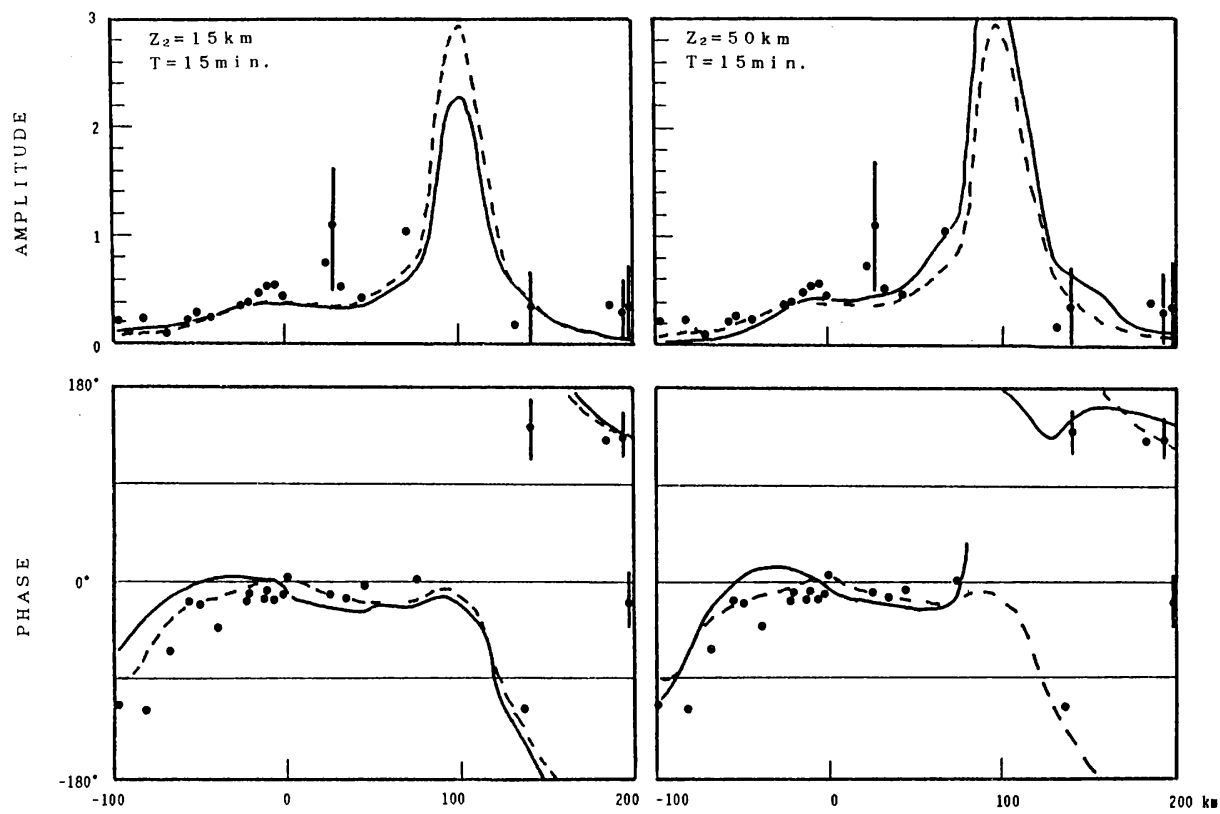

(a)
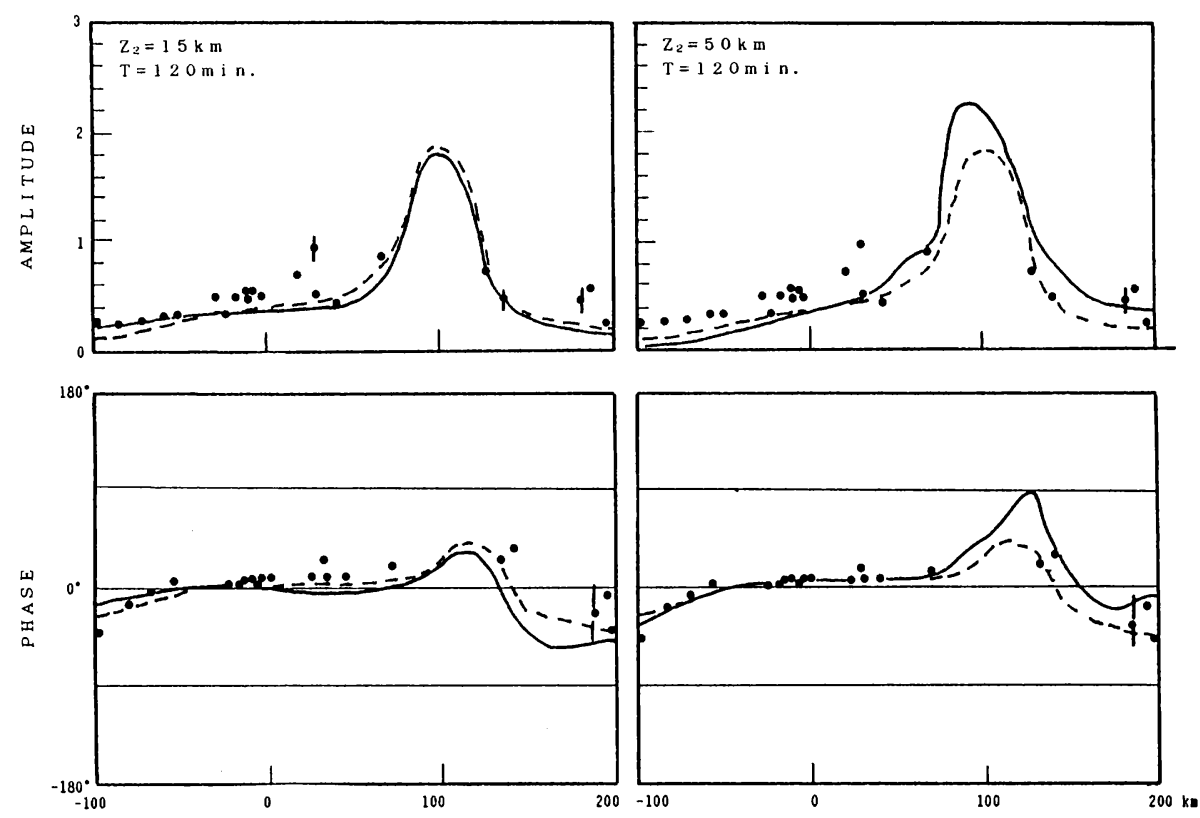

(b)

Fig. 11. (a) Calculated responses when the depth to the Philippine Sea conductor, $Z_{2}$, is taken to be $15 \mathrm{~km}$ (left) and $50 \mathrm{~km}$ (right) at the periods of 15 minutes. Dashed liens are those for the final model $\left(Z_{2}=30\right.$ $\mathrm{km}$ ). (b) Calculated responses when $Z_{2}$ is taken to be $15 \mathrm{~km}$ (left) and $50 \mathrm{~km}$ (right) at the periods of 120 minutes. 

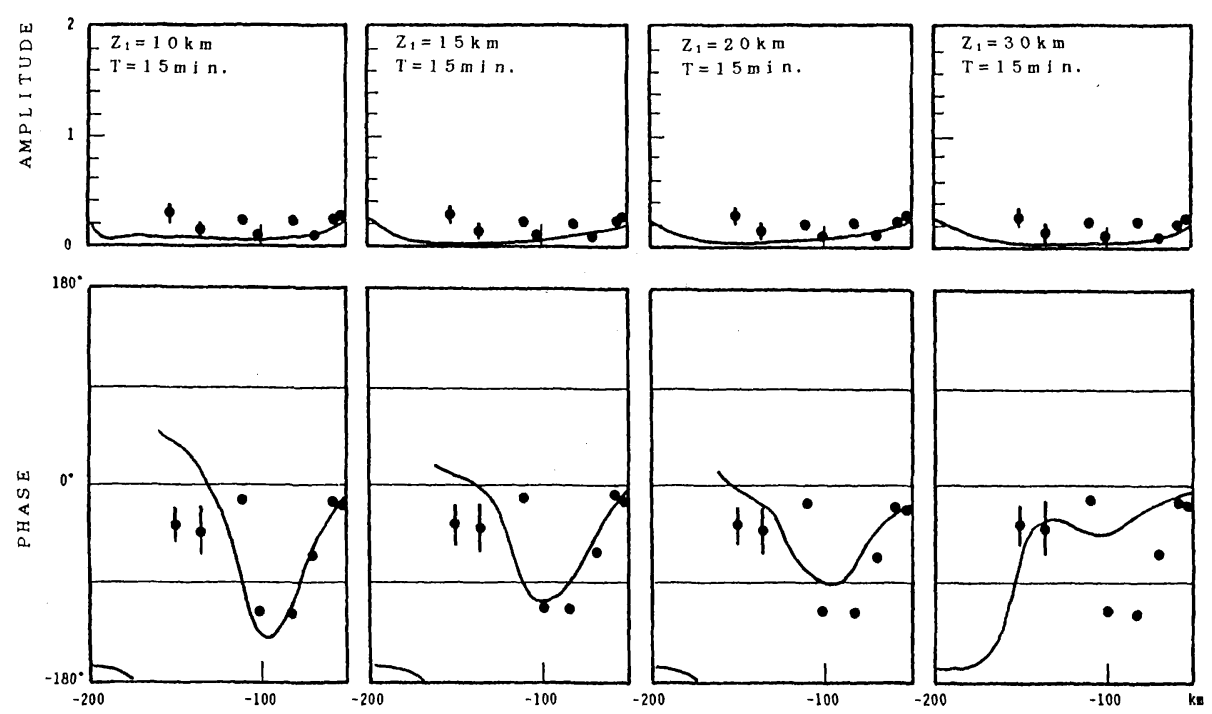

(a)
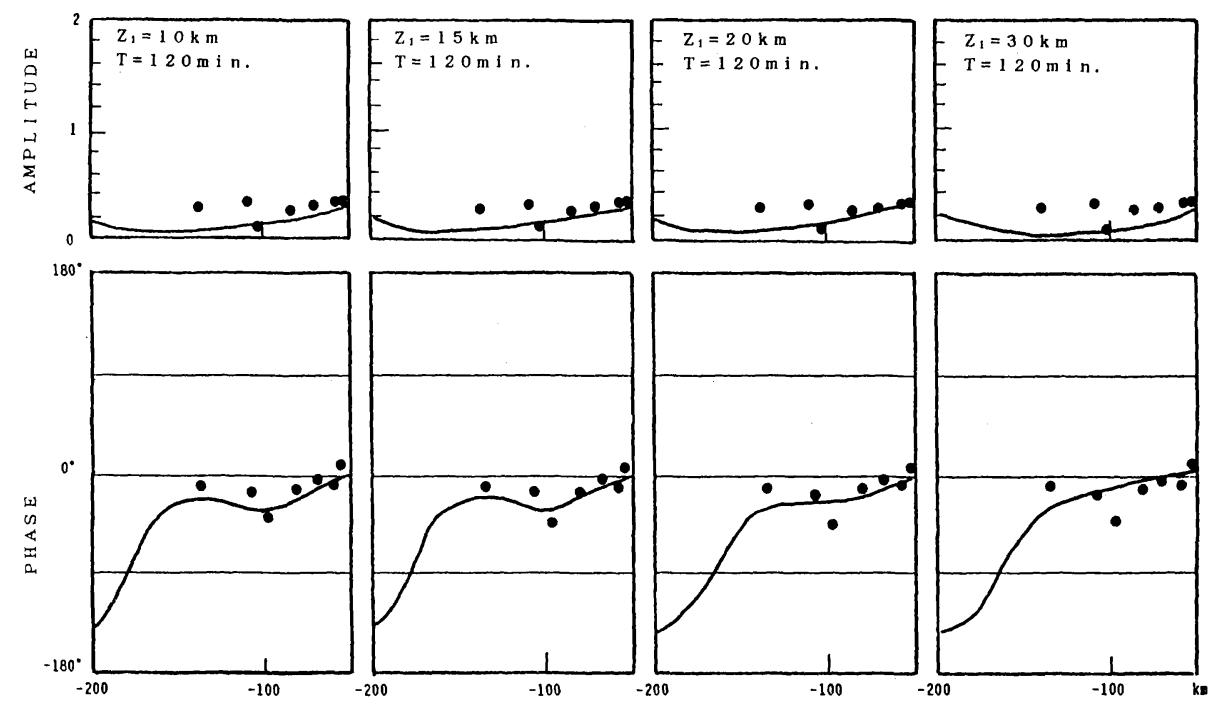

(b)

Fig. 12. (a) Calculated responses when the depth to the crustal conductor, $Z_{1}$, is taken to be $10,15,20$ and $30 \mathrm{~km}$ from left to right, respectively, at the period of 15 minutes. (b) Same as Fig. 12(a) at the period of 120 minutes. 

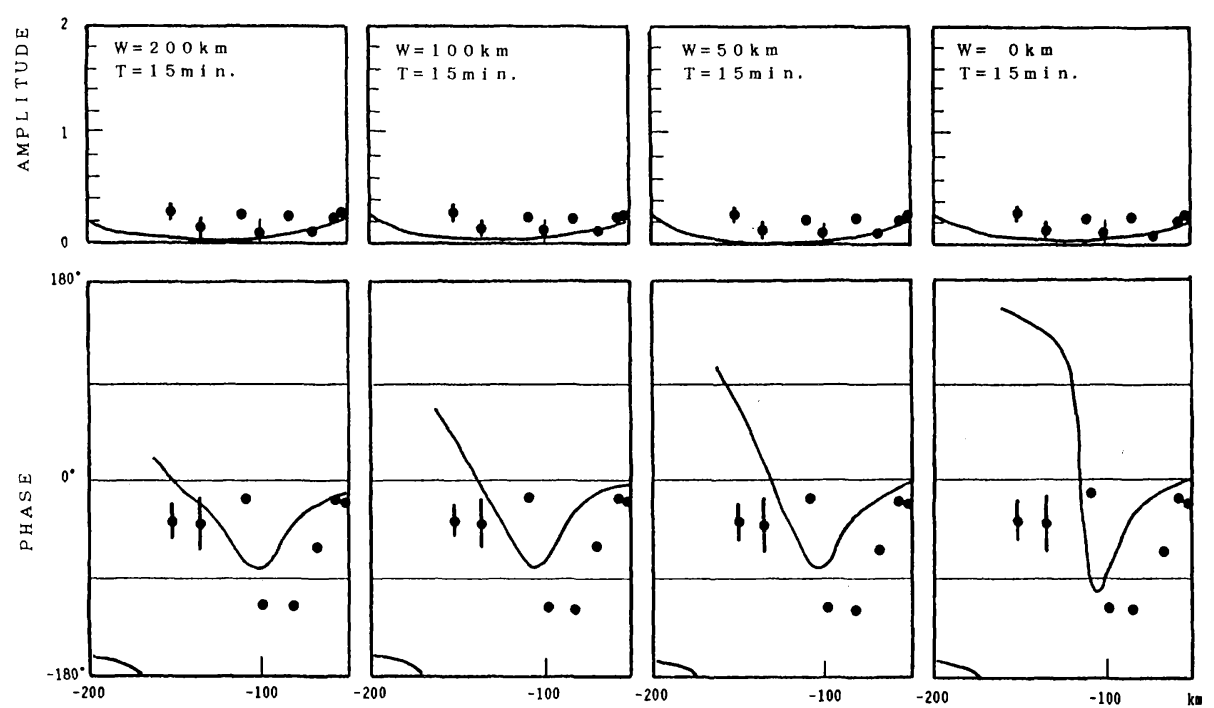

(a)
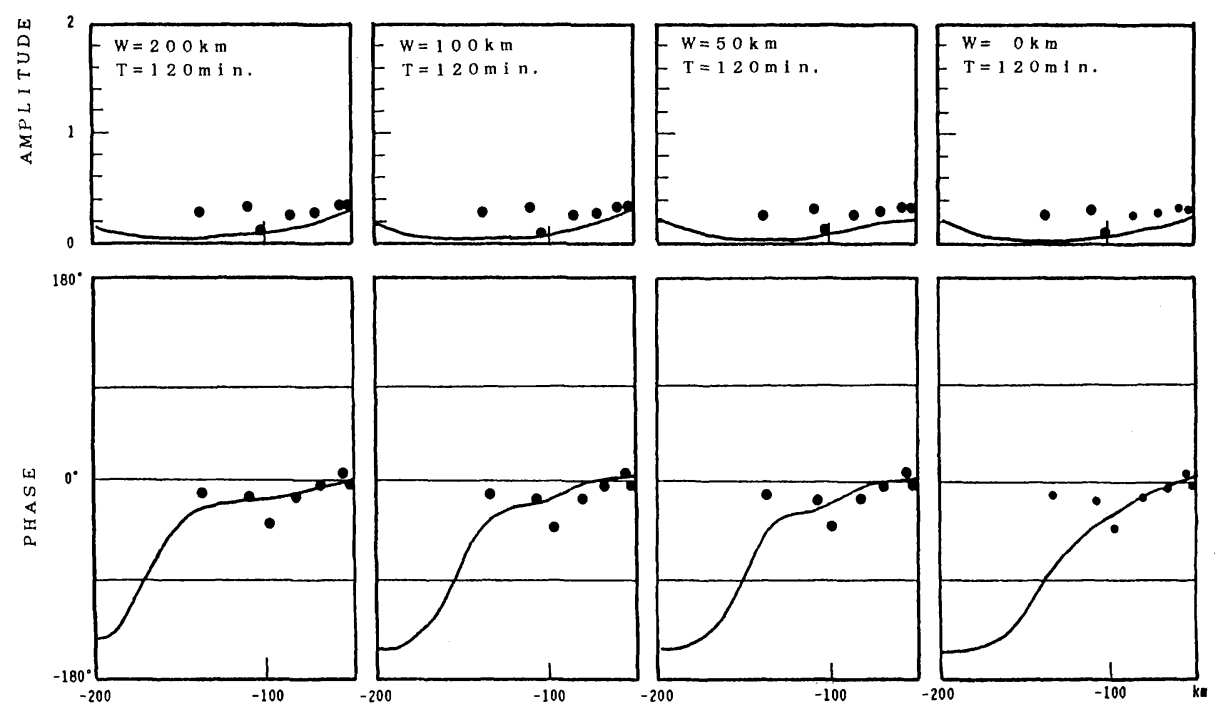

(b)

Fig. 13. (a) Calculated responses when the distance from the Japan Sea coast to the edge of upper mantle conductivity, $W$, is taken to be $200,100,50$ and $0 \mathrm{~km}$ from left to right, respectively, at the period of 15 minutes. (b) Same as Fig. 13(a) at the period of 120 minutes. 
modifies this induction effect by mutual coupling, resulting in poorer fit to the observed responses.

\section{Discussion and Conclusions}

HONKURA (1974) presented a conductivity model to explain the spatial and period dependence of observed transfer functions by introducing highly conductive layers with conductivity of $0.5 \mathrm{~S} / \mathrm{m}$ at the depth of $30 \mathrm{~km}$ beneath the Philippine and the Japan Sea floor. As for the Philippine Sea side, our result is fairly consistent with his model, except for a slight difference in conductivity value. It has been pointed out by many investigators (e.g., FILLOUX, 1980) that such a conductor with conductivity of about $0.1 \mathrm{~S} / \mathrm{m}$ is commonly observed beneath the moving oceanic plate, which possibly corresponds to the top of the asthenosphere. The cause of the high conductivity is usually considered as partial melting in the upper mantle.

The present results indicate a high conductive layer beneath the Philippine Sea, whereas non-existence, within at least $200 \mathrm{~km}$ from the coast, of such a high conductive layer beneath the Japan Sea is suggested. This is a puzzle because the observed heat flow is high in the Japan Sea, implying the high temperature state and possibly the existence of partial melting. One possible explanation is to assume stress sensitivity of bulk conductivity of partially melted asthenosphere.

Based on a theoretical model, Hamano (1986, in preparation) suggests that the bulk conductivity of the asthenosphere is highly sensitive to the applied stress. Under a stress free condition, the bulk conductivity of the asthenosphere increases only slightly even if the melt fraction is sufficiently large, unless the melted regions are interconnected to each other. When a shear stress is applied to the asthenosphere by the plate motion, each melted region is elongated to enhance the interconnectivity of melts and, as a result, to increase its bulk conductivity with high anisotropy. This might be useful to solve the puzzle. If the spreading of the Japan sea was different from the ordinary plate motion and the most of the melted regions are in a state of isolation, the bulk conductivity can not be high. Of course there remains a possibility that a highly conductive layer exists far from the coast beneath the Japan Sea, so to say beneath the Japan Basin. Further detailed measurements will make it possible to clarify these uncertainties in the electrical structure beneath the Japan Sea.

Figure 14 shows the actual coverage of the lower crustal conductor beneath Central Japan. It is noted that many of the Quaternary volcanoes denoted by solid triangles are included in this conductive area. OGAWA et al. (1985) presented a conductivity model for Northeast Japan with a lower crustal conductor. In their model, the eastern edge of the high conductor is coincident with the volcanic front in the region. Similar result was obtained by magnetotelluric sounding (RESEARCH Group For Crustal Resistivity STRUCTURE, JAPAN, 1983; YukUtAKe, 1985). These observations and the present results for Central Japan suggest that there exists some relationship between volcanic activities in both areas and conductive lower crust.

Many petrological investigations suggest that the lower crust of active island arc including Northeast Japan is generally composed of mafic rocks with hydrated minerals like hornblend gabbro or amphibolite (TAKAHASHI, 1978; CONRAD and KAY, 1980), and water, which is necessary for hydration, is considered to be supplied 


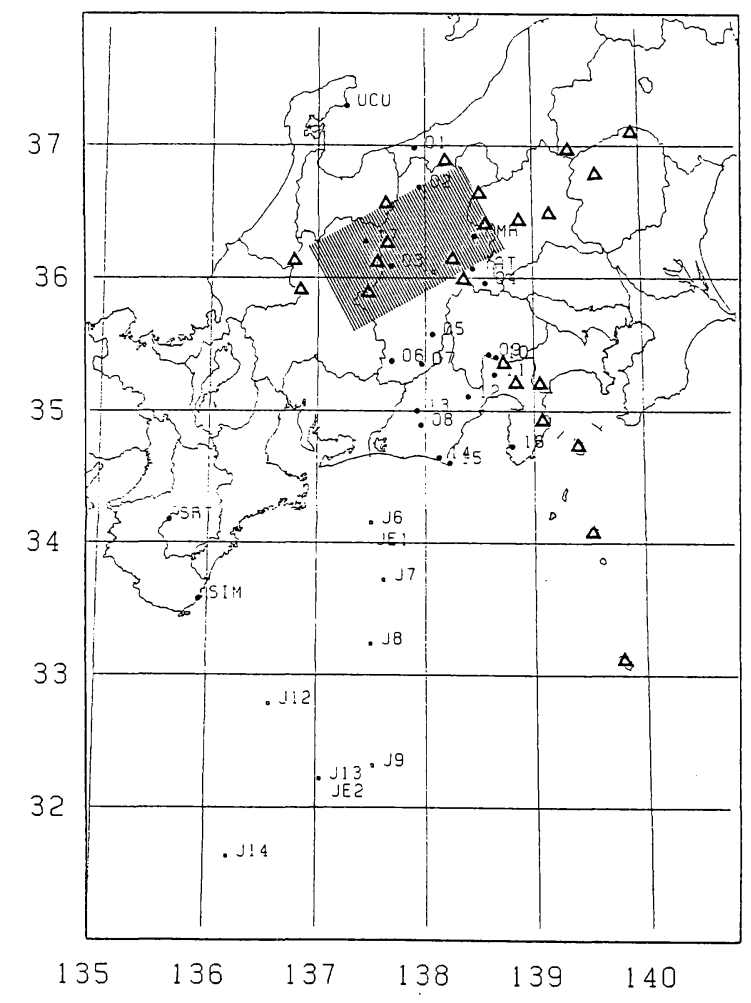

Fig. 14. The crustal conductor beneath Central Japan (hatched area). Triangles denote the Quaternary Volcanoes.

continuously from the plate by means of dehydration of oceanic plate which begins below the volcanic front. On the other hand, there also are many petrological evidences that lower crustal rocks beneath Southwest Japan are widely composed of almost the same rock-forming minerals in chemical composition but they are unhydrated (FUJII, 1984). This difference is interpreted as follows; the South-western part of Japan is located too far from the tip of the subduction plate for water to be supplied from below, while there is continuous water supply from the oceanic plate to the lower crust in the eastern part.

It is shown by laboratory experiments that, under some thermal condition, free water possibly exists in the crustal rocks at the depths between $20 \mathrm{~km}$ and $25 \mathrm{~km}$ (SHANKLAND and ANDER, 1983). Lower crustal rocks, which are highly resistive in dry state (KARIYA and SHANKLAND, 1983), will become remarkably conductive if free water exists, as was shown by OLHOEFT (1981) and SHANKLAND and ANDER (1983). This seems to be a plausible cause of high conductivity in the lower crust beneath Central and Northeast Japan. At lower depth, partial melting may be a dominant factor for conductivity increase because the existence of water efficiently reduces the solidus of the rock (FUJII, 1984).

Several results of seismic observation have disclosed that the $\mathrm{S}$ waves travelling 
beneath the Hida mountain area are strongly attenuated (KoNo et al., 1985). The area is supposed to be localized at such a depth as about $10 \mathrm{~km}$. The cause of this high attenuation region was attributed to the existence of melt. However, the region is supposed to be different from our conductive layer because of its depth and extremely localized nature, but they seem to be connected by a common cause. Existence of free water in the lower crust increases its conductivity, while it also reduces the solidus and causes a partial melting zone. The high attenuation region possibly corresponds to the magma reservoir, to which magma is supplied from the deeper partial melting zone.

In the present investigation, three features have been revealed for the geoelectric structure beneath the central part of Japan. One is existence of a highly conductive layer beneath the Philippine Sea plate, at such a shallow depth as $30 \mathrm{~km}$. This is supposed to be caused by partial melting near the surface of the asthenosphere. The second feature is another conductive layer occurring at a depth of about $20 \mathrm{~km}$ in the northern part of Central Japan, suggesting the lower crust is conductive in this region. This may be ascribed to existence of free water in the lower crust. The third feature is non-existence of a conductive layer beneath the Japan Sea. The last two features are similarly seen in Northeast Japan, where the lower crust is conductive on th Japan sea side of the volcanic front, with no indication of conductor below the Japan Sea. However, the Philippine Sea plate is clearly different from the Pacific plate, because the conductive layer is as deep as $150 \mathrm{~km}$ in the vicinity of the Japan Trench (YUKUTAKE et al., 1983), perhaps suggesting difference in the thickness of the plate.

Most of the land site data, analysed in this study, were obtained by the Research Group for Crustal Resistivity at the cooperative project in 1982. Sea floor observations were carried out in cooperation with Dr. Segawa, Ocean Research Institute, to whom we are very grateful for his efforts in many respects of the experiments. Mr. Sasai, Earthquake Research Institute, is acknowledged for providing us with the land site data at UCU, KMR and SIM.

\section{REFERENCES}

Bendat, J. S. and A. G. Piersol, Random Data: Analysis and Measurements, 407pp., Wiley-Interscience, New York, 1971.

CONRAD, W. and R. W. KAY, Petrology and significance of olivine and amphibole bearing xenoliths in Aleutian andesites (abstract), EOS Trans. AGU, 61, 400, 1980.

Everett, J. E. and R. D. Hyndman, Geomagnetic variations and electrical conductivity structure in south- western Australia, Phys. Earth Planet. Inter., 1, 24- 34, 1967.

FIllouX, J. H., Magnetotelluric sounding over the north- east Pacific may reveal spatial dependence of depth and conductance of the asthenosphere, Earth Planet. Sci. Lett., 46, 244-252, 1980.

Filloux, J. H., Magnetotelluric exploration of the North Pacific: progress report and preliminary soundings near a spreading ridge, Phys. Earth Planet. Inter., 25, 187-195, 1981.

FujII, T., Petrological models of lower crust, in Proc. Conductivity Anomaly Sym., Earthq. Res. Inst., Univ. Tokyo, pp. 25-34, 1984 (in Japanese).

Honkura, Y., Electrical conductivity anomalies beneath the Japan arc, J. Geomag. Geoelectr., 26, 147-171, 1974.

Honkura, Y., Partial melting and electrical conductivity anomalies beneath the Japan and Philippine Seas, Phys. Earth Planet. Inter., 10, 128-134, 1975.

Honkura, Y., Peninsula effects in central Japan and their relation to the electrical conductivity structure, J. Geomag. Geoelectr., 35, 39-56, 1983.

KANAmORi, H. and K. ABE, Deep structure of island arcs as revealed by surface waves, Bull. Earthq. Res. Inst., Univ. Tokyo, 46, 1001-1025, 1968.

KARIYA, K. A. and T. J. ShAnKLAND, Electrical conductivity of dry lower crustal rocks, Geophysics, 48, 
$52-61,1983$.

Kono, Y., S. Kanai, H. Wada, M. Mizoue, and I. Fujil, Anomalous attenuation of seismic waves under the Hida mountain range and its cause (abstract), Bull. Volcanol. Soc. Japan, 30, 114, 1985 (in Japanese).

Maritime Safety Agency, The result of magnetic observations for the year 1979, Data Rep. Hydrogr. Obs., Ser. Geomagnetism, 15, 1981.

Ogawa, Y., T. YukUtake, and H. UTAda, Two dimensional modelling of resistivity structure beneath the Tohoku district, northern Honshu of Japan, by a finite element method, J. Geomag. Geoelectr., 38, 45-79, 1985.

Oldenburg, D. W., Conductivity structure of oceanic upper mantle beneath the Pacific plate, Geophys. J. R. Astron. Soc., 65, 359-394, 1981.

OlHoeft, G. R., Electrical properties of granite with implications for the lower crust, J. Geophys. Res., 86, 931-936, 1981.

Porath, H. and A. Dziewonski, Crustal resistivity anomalies from geomagnetic deep-sounding studies, Rev. Geophys. Space Phys., 9, 891-915, 1971.

REDDY, I. K. and D. RANKIN, Magnetotelluric response of latelally inhomogeneous and anisotropic media, Geophysics, 40, 1035-1045, 1975.

Research Group for Crustal Resistivity Structure, Japan, Preliminary report on a study of resistivity structure beneath the northern Honshu of Japan, J. Geomag. Geoelectr., 35, 589-608, 1983.

RiKITAKE, T., The undulation of an electrical conductive layer beneath the island of Japan, Techtonophys., 7, 257-264, 1969.

Rikitake, T., A model of geoelectric structure beneath Japan, J. Geomag. Geoelectr., 27, 233-244, 1975.

Rikitake, T. and I. Yokoyama, Anomalous relations between $H$ and $Z$ components of transient geomagnetic variations, J. Geomag. Geoelectr., 5, 59-65, 1953.

Rikitake, T. and Y. Honkura, Recent Japanese studies on conductivity anomalies, Phys. Earth Planet. Inter., 7, 203-212, 1973.

Sasai, Y., Observations of geomagnetic variation in Kii Peninsula, in Proc. Conductivity Anomaly Symp., 2. Earthq. Res. Inst., Univ. Tokyo, pp. 43-55, 1969 (in Japanese).

Segawa, J., T. Yukutake, Y. Hamano, T. Kasuga, and H. Utada, Sea floor measurement of geomagnetic field using newly developed ocean bottom magnetometers, J. Geomag. Geoelectr., 34, $571-585,1982$.

Shankland, T. J. and M. E. Ander, Electrical conductivity, temperature, and fluid in the lower crust, $J$. Geophys. Res., 88, 9475-9484, 1983.

Takahashi, E., Petrologic model of the crust and upper mantle of the Japanese Island arcs, Bull. Volcanol., 41, 529-547, 1978.

Watanabe, T., Temperature profiles at continental margin, in Proc. Conductivity Anomaly Symp., Earthq. Res. Inst., Univ. Tokyo, pp. 167-182, 1968

Yukutake, T., Electromagnetic observations in Tokai- Koushin'etsu District, in Proc. Conductivity Anomaly Symp., Earthq. Res. Inst., Univ. Tokyo, pp. 35-44, 1984 (in Japanese).

YUKUTAKE, T., A review of studies on the electrical resistivity structure of the crust in Japan, Earthq. Predict. Res., 3, 345-364, 1985.

Yukutake, T., J. H. Filloux, J. Segawa, Y. Hamano, and H. Utada, Preliminary report on a magnetotelluric array study in the northwest Pacific, J. Geomag. Geoelectr., 35, 575-587, 1983. 